\title{
Die Foraminiferen der Nordsee
}

\author{
B. GABEL \\ Deutsches Hydrographisches Institut; Hamburg, Bundesrepublik Deutscbland
}

\begin{abstract}
The foraminiferans of the North Sea. This paper presents a brief description of the most common method of sampling foraminiferans from recent sediments and of the foraminiferan fauna of the North Sea. Distribution charts of foraminiferans in the North Sea demonstrate the influence of the Atlantic Ocean water with a slightly higher salinity in the northern part. With the exception of some very rare forms, the recent North Sea Foraminifera are illustrated and their genera briefly characterized. One new species, Trifarina pygmaea spec. nov, is described.
\end{abstract}

\section{EINLEITUNG}

Nachdem von Zregelmeier. $(1957,1966)$ die Muscheln und die Schnecken der deutschen Meeresgebiete bearbeitet worden sind, sollen hier in der gleichen Weise die Foraminiferen der Nordsee behandelt werden. Dabei ist nicht an eine erschöpfende Bearbeitung und an eine Aufstellung von Synonymie-Listen gedacht, vielmehr soll diese Darstellung dem weniger Eingearbeiteten und dem Laien eine Übersicht geben und eine Hilfe bei der Bestimmung sein. Bei der intensiven Forschungsarbeit auf diesem Gebiet ist es selbstverständlich, daß laufend neue Arten aufgestellt oder bestehende Namen geändert werden, was man bei einem Vergleich mit anderen Arbeiten beachten sollte. Für genauere Bearbeitungen empfiehlt es sich in jedem Fall, die Original-Literatur heranzuziehen.

PoKorny (1958, p. 88) gibt folgende Definition der Foraminiferen: „Die Foraminiferen sind Rhizopoden, die bis auf ganz unbeträchtliche Ausnahmen ein festes einoder mehrkammeriges Gehäuse besitzen, das entweder rein sekretorischen Ursprungs (aus Tektin, Opal, Kalziumkarbonat) oder agglutiniert ist. Das Protoplasma erfiillt das ganze Gehäuse und tritt durch eine oder mehrere Offnungen heraus, wobei es echte Rhizopodien bildet. Meistens marin, nur einige sehr primitive Formen im Süßwasser. Kambrium - rezent."

Die agglutinierenden Formen bauen ihr Gehäuse vorwiegend aus Sandkörnern auf, gelegentlich werden aber auch Mineralmehl, Schwammnadeln, Schlickpartikel oder - bei einigen Großformen - Schalen von kleinen Foraminiferen und kleine Steinchen verwandt. Manchmal ist ein deutlicher Zusammenhang zwischen der Korngröße des zum Schalenaufbau verwandten Materials und der des umgebenden Sediments zu beobachten (Taf. 1; 1 und 2). 
Die Größe der Foraminiferen beträgt im allgemeinen 0,2 bis $0,5 \mathrm{~mm}$. Riesenformen, die bis zu $80 \mathrm{~mm}$ erreichen können, kommen nur ausnahmsweise vor. Ihrer Lebensweise entsprechend, unterscheidet man zwei Gruppen:

(1) Die planktischen Foraminiferen: Sie sind weltweit verbreitet, die Artenzahl ist relativ gering; in der sïdlichen Nordsee spielen sie nur eine ganz untergeordnete Rolle.

(2) Die benthischen Foraminiferen: Ihr Arten- und Formenreichtum ist erheblich höher als bei den planktischen Formen. Sie leben an der Oberfläche oder in den obersten Zentimetern (maximale Tiefe: $15 \mathrm{~cm}$ ) des Sediments auf dem Meeresboden, meist frei beweglich (vagil), seltener festgeheftet (sessil). Die Mehrzahl von ihnen verlangt wie die planktischen Foraminiferen salzreiches Wasser; nur wenige Arten können sich den Lebensbedingungen des Brackwasserbereiches anpassen. Völlig ungeeignet als Lebensraum sind die im Gezeitenbereich trockenfallenden Wattgebiete und Strände.

\section{GEWINNUNGSMETHODEN}

Mit Hilfe eines geeigneten Entnahmegerätes (Bodengreifer, Stechkasten oder ähnlichen Geräten) wird vom Meeresboden eine Sedimentprobe entnommen, wobei darauf $z u$ achten ist, daß der natürliche Schichtverband nicht zu sehr gestört wird. Von dieser Probe werden die obersten ein bis zwei cm vorsichtig für die weitere Bearbeitung abgehoben. Ist eine meist dunkler gefärbte Reduktionsschicht im Sediment vorhanden, so sollte sie beim Abheben nicht mehr mit einbezogen werden. Die für die weitere Bearbeitung benötigte Materialmenge beträgt erfahrungsgemäß in der südlichen Nordsee ca. $500 \mathrm{~g}$, in der stärker besiedelten nördlichen Nordsee reichen $100 \mathrm{~g}$ aus.

Oft ist es erwünscht, die Schalen der Tiere, die zur Zeit der Probennahme leben, von denen der bereits abgestorbenen Tiere oder gar angespülten Schalen zu unterscheiden. In diesem Fall ist ein Anfärben des lebenden Plasmas erforderlich. Sehr gut bewährt hat sich hierfür der: Farbstoff Bengalrosa, der in Methanol oder in Spiritus im Verhältnis $1 \mathrm{~g}$ Farbstoff auf $1000 \mathrm{ccm}$ Flïssigkeit gelöst wird. Die Probe wird dazu in einen gut verschließbaren Behälter (Plastikflasche mit weitem Hals) gebracht. Dann wird soviel von der Färbeflüssigkeit zugegeben, bis das Sediment gut bedeckt ist und alle Partikeln ausreichend angefärbt werden können. Die Probe wird gut durchgeschüttelt und bleibt bis zur weiteren Bearbeitung in dem Gefäß stehen. Uberschüssige Färbeflüssigkeit sollte nicht abgegossen werden.

\section{AUFARBEITUNG IM LABOR}

Man befreit die Probe im Labor von der feinen Tontrübe und gegebenenfalls von überschüssigem Farbstoff durch Ausschlämmen über einem Sieb mit einer Maschenweite von $0,063 \mathrm{~mm}$. Am besten geschieht das mit einer Handdusche, bei stark bindigen Sedimenten kann die Schlämmung mit einem weichen Pinsel unterstützt werden. Dabei ist darauf zu achten, daß das Sediment nicht mit Gewalt durch die Siebmaschen gedrückt wird und die zarten Foraminiferenschalen nicht zerbrochen werden. Anschließend wird das Siebgut bei einer Temperatur von $80^{\circ}$ bis $100^{\circ} \mathrm{C}$ getrocknet. 
Zur Gewinnung der Foraminiferen aus dem Sand schwemmt man das trockene Siebgut mehrmals mit Tetrachlorkohlenstoff (spez. Gewicht 1,596) auf. Dabei fallen die Sandkörner zu Boden, die teilweise mit Luft gefüllten Schalen schwimmen an der Oberfläche und können über ein Filter abgegossen werden. Da eine solche Trennung selten vollständig ist und viele agglutinierte Formen dazu neigen, mit in die Sandfraktion zu gehen, empfiehlt es sich, auch den Rückstand unter dem Binokular nach Foraminiferen durchzusehen.

Das weitere Auslesen geschieht unter einer Binokularlupe mit 30-bis 50facher Vergrößerung. Mit einer Auslesenadel, die man sich leicht aus einer Nähnadel und einem Holzgriff selber herstellen kann und die man durch Einstechen in Stearin oder Bienenwachs mit einem Haftfilm ïberzieht, lassen sich die Foraminiferen aufnehmen und in Franke-Zellen abstreifen. (Ausleseschalen, Franke-Zellen etc. liefert die Firma Fema, 3327 Salzgitter-Bad, Friedrich-Ebert-Straße 53.)

\section{VERBREITUNG DER FORAMINIFEREN IN DER NORDSEE}

JARKE (1961, p. 28 ff.) diskutierte ausführlich die Verbreitung der Nordsee-Foraminiferen in ihrer Abhängigkeit von den hydrographischen Verhältnissen und den Sedimenten. Er streicht heraus, daß die planktischen Foraminiferen im wesentlichen auf die nördliche Nordsee beschränkt sind und in der südlichen Nordsee nur ausnahmsweise in Streifen vorkommen (Abb. 1). Hauptursache dafür ist die Empfindlichkeit der planktischen Foraminiferen gegenüber einer auch nur geringen Herabsetzung des Salzgehaltes. Die Vermischung des normalsalzigen Ozeanwassers mit dem Nordseewasser, das eine etwas geringere Salzkonzentration hat, führt zu einem Absterben der Tiere.

Eine Neubearbeitung des Jarkeschen Materials ergab, daß die in der südlichen Nordsee auftretenden planktischen Foraminiferen ausschließlich juvenile Exemplare von Globigerina pachyderma sind, während die späte Form dieser Art nur im Norden zu finden ist. Nach BÉ (1960) muß man bei Globigerina pachyderma ein frühes Entwicklungsstadium, das im oberflächennahen Wasser lebt, von einer späteren Form unterscheiden, die das Sediment als Lebensraum bevorzugt. Die Verteilung von Globigerina pacbyderma in der Nordsee zeigt, daß die planktisch lebenden Exemplare zwar gelegentlich in die südliche Nordsee verdriftet werden können, dort aber ungeeignete Lebensbedingungen vorfinden und sich nicht weiterentwickeln können.

Auch die benthischen Foraminiferen haben ihr Hauptverbreitungsgebiet in der nördlichen Nordsee (Abb. 2). JARKE bietet dazu verschiedene Erklärungsmöglichkeiten an, betont aber, daß bei dem derzeitigen Wissensstand viele Fragen noch offenbleiben müssen. Neben verschiedenen anderen Faktoren spielt sicherlich die Intensität der Wasserbewegung am Meeresgrund eine Rolle, die gerade in der flachen südlichen Nordsee hohe Werte erreichen kann. Häufige Sedimentaufwirbelungen und Umlagerungen erschweren die Lebensbedingungen für die Foraminiferen und zerstören deren Gehäuse. Neben einigen zarten Kalkschalern (z. B. Lageniden, Buliminiden) werden besonders die agglutinierenden Formen leicht zerbrochen, wie es bei der in Abbildung 3 dargestellten Verteilung deutlich wird. Am widerstandsfähigsten gegen Umlagerungen sind massive Formen wie Ammonia beccarii und Quinqueloculina seminula. Beide Arten haben daher 


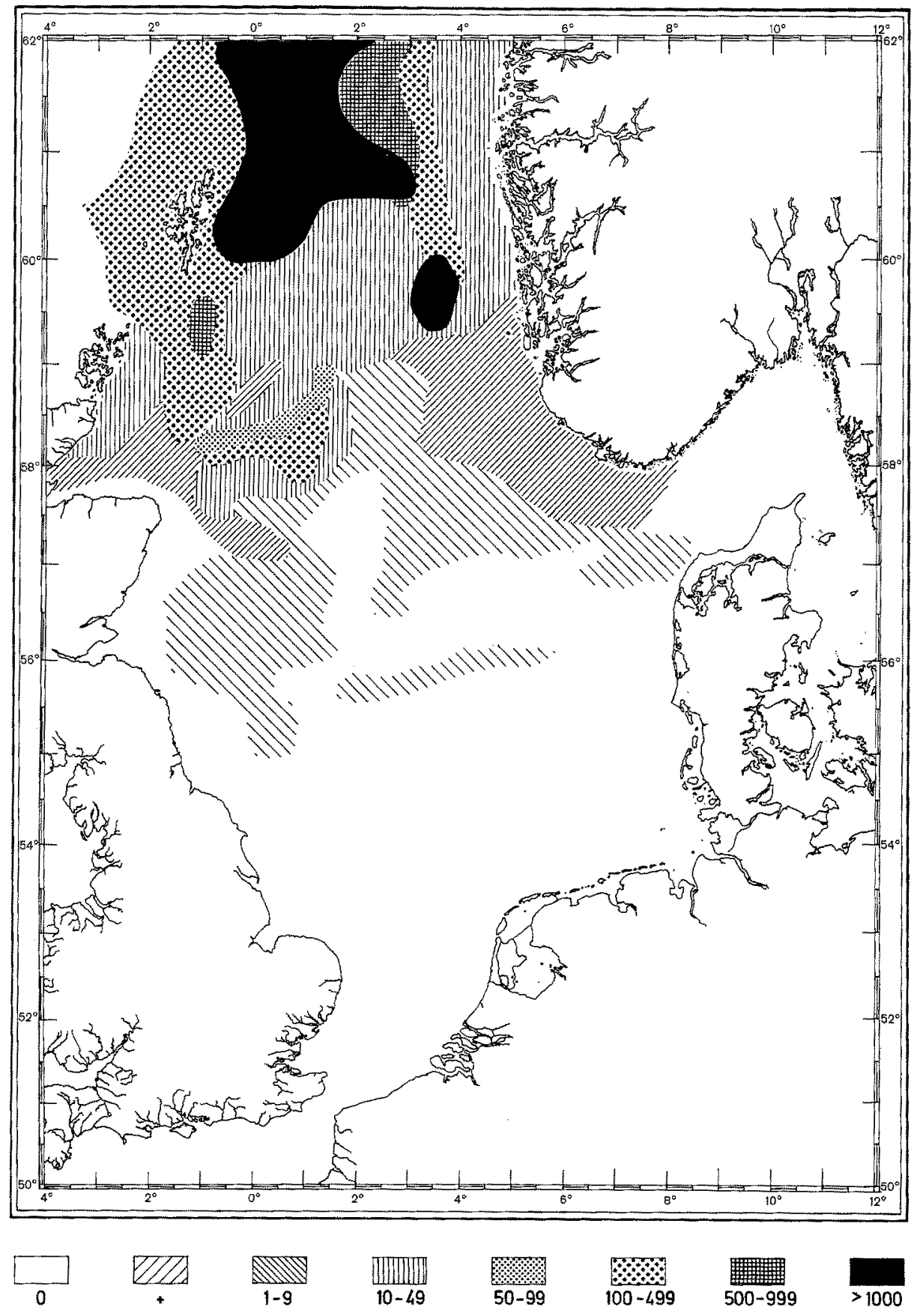

Abb. 1: Anzahl der planktischen Foraminiferen in $1 \mathrm{~g}$ Sediment in der Nordsee. (Nach GabeL aus JARKE 1961, verändert) 

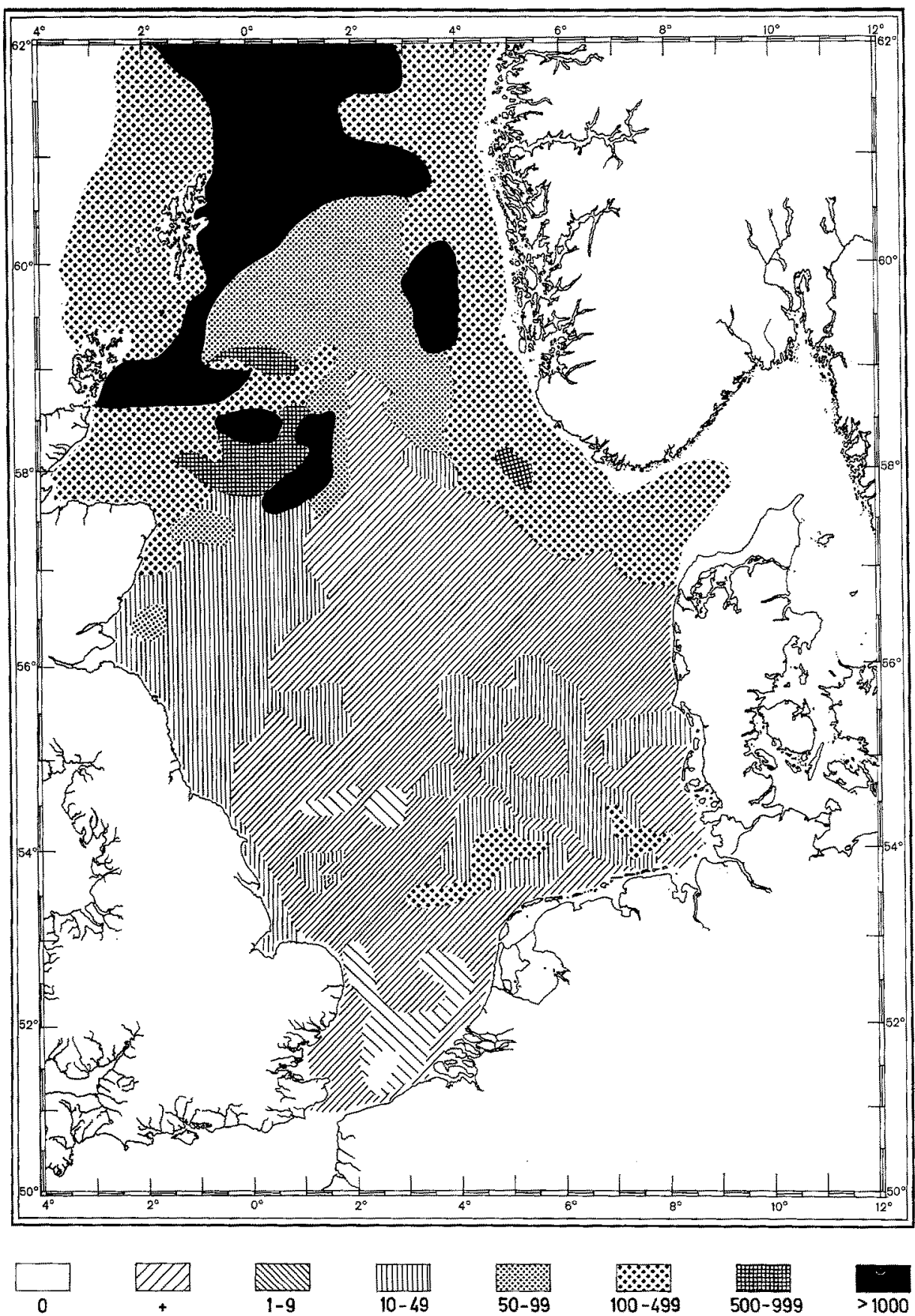

Abb. 2: Anzahl der benthischen Foraminiferen in $1 \mathrm{~g}$ Sediment in der Nordsee. (Nach GABel aus JARKE 1961, verändert) 


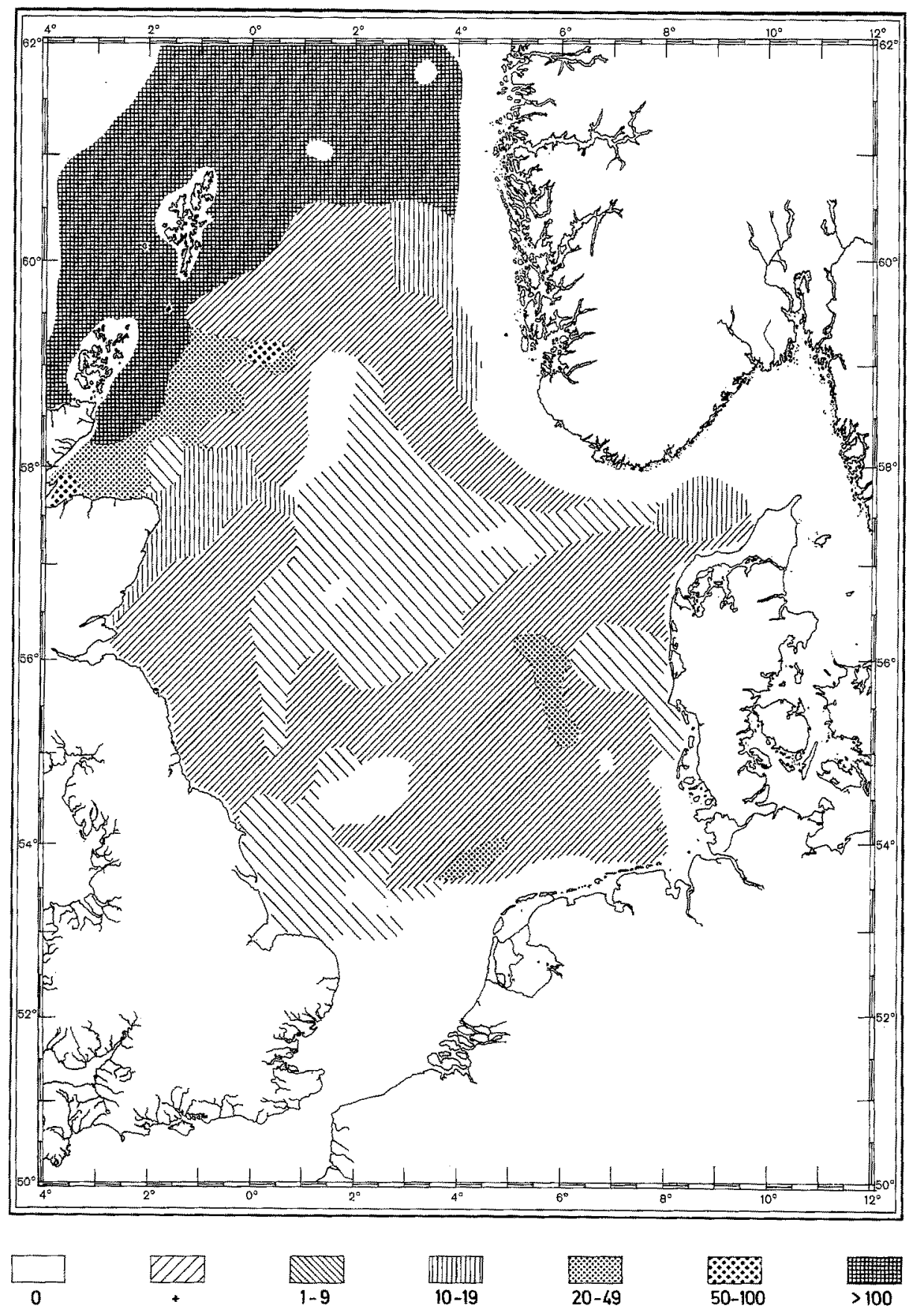

Abb. 3: Anteil der agglutinierten Formen bei den benthischen Foraminiferen in der Nordsee in \%. (Nach GABEL aus JARKE 1961, verändert) 


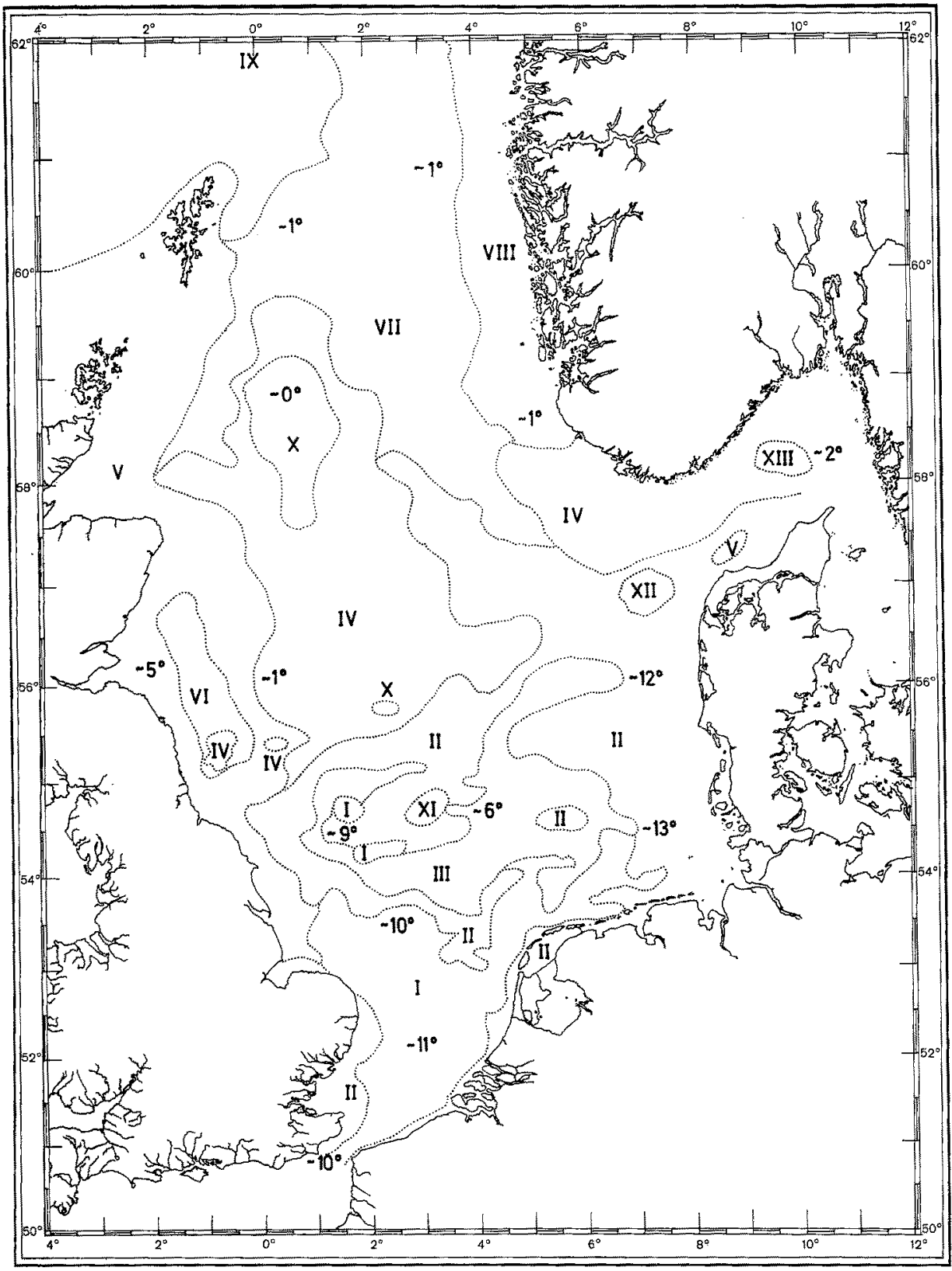

Abb. 4: Provinzen der vorherrschenden Foraminiferenarten in der Nordsee. Anteil meist über $50 \%$ der Foraminiferen-Vergesellschaftung. I Ammonia beccarii, Quinqueloculina seminula; II Cribrononion incertum, Nonion depressulum; III Eggerella scabra, Verneuilina media, Cribrononion incertum; IV Bulimina fusiformis, $B$. marginata; V Planorbulina mediterranensis; VI Cibicides lobatulus; VII Cassidulina norcrossi; VIII Uvigerina peregrina, Trifarina angulosa; IX Islandiella norvangiz; X Hyalina balthica; XI Rosalina bradyi, Neoconorbina terquemi, Florilus cf. asterizans; XII Textularia truncata; XIII Brizalina spatbulata. Die Zahlen geben die mittleren Schwankungen der Jahrestemperatur an. (Nach GABEL aus JARKE 1961, verändert) 
auch im Gebiet der Hoofden, in dem sehr starke Sandverlagerungen stattfinden, einen Anteil von über 50\% aller vorkommenden Foraminiferenschalen (Abb. 4).

\section{BESTIMMUNG}

Für die Bestimmung nach den am Schluß dieser Arbeit gegebenen 20 Tafeln sind die Foraminiferengattungen nach Familien geordnet und kurz charakterisiert. Ein Bestimmungsschlïssel, wie ihn z. B. ZiegelmeIER $(1957,1966)$ für die Muscheln und die Schnecken gibt, läßt sich für Foraminiferen nicht aufstellen; die Unterscheidung geschieht ausschließlich nach den Schalenmerkmalen.

Wesentliche Bedeutung haben dabei Gehäuseform, Proloculus, Zahl, Form, Größe und Anordnung der Kammern, Mündungsformen (vgl. Taf. 20) und Aufbau der Wände.

Der Proloculus, die Anfangs- oder Embryonalkammer, kann - bedingt durch Generations-Dimorphismus - bei der gleichen Art makrosphärisch (= megalosphärisch, groß) oder mikrosphärisch (klein) sein. Die Anordnung der dem Proloculus folgenden Kammern kann sein: uniserial (in einer Reihe stehend), z. B. Nodosaria (Taf. 9), biserial (in zwei Reihen stehend) z. B. Brizalina (Taf. 14), triserial (in drei Reihen, dabei oft spiralig um die Achse gedreht), z. B. Eggerella (Taf. 5), virgulin (zopfartig verflochten), z. B. Stainforthia (Taf. 14), rotalid (spiralförmig aufgewunden, wobei die Kammerscheidewände oft auf der Ventralseite deutlicher erkennbar sind), z. B. Ammonia (Taf. 17), trochoid und trochospiral (schneckenförmig), z. B. Eponidus (Taf. 16), discoidal (in der Ebene aufgerollt), entweder evolut, z. B. Spirilina (Taf. 15), oder involut, z. B. Elpbidium (Taf. 13). Suturen oder Nähte sind Verbindungslinien der Kammerscheidewände mit dem Gehäuse.

Gelegentlich findet man in der Nordsee fossile Formen aus aufgearbeiteten alten, vorwiegend kretazischen Sedimenten. Sie werden bei den Beschreibungen und Abbildungen nicht mit berïcksichtigt.

\section{TAXONOMISCHE ÜBERSICHT*}

\section{Allogromidae}

Gehäuse frei, aus Tektin, seltener agglutiniert. Im getrockneten Sediment meist zerstört. Vorkommen: Im Süßwasser, im Brackwasser, seltener marin.

\section{Astrorhizidae}

\section{Astrorbiza SANDAHL 1858}

Diese Gattung gehört $\mathrm{zu}$ den primitivsten agglutinierenden Foraminiferen. Eine Zentralkammer, irregulär, mit zwei oder mehreren Armen. Im Inneren Tektintapete, äuße-

\footnotetext{
* In zum Teil enger Anlehnung an PoKorny (1958).
} 
rer Körper agglutiniert, je nach Angebot des Sediments, fein bis grob. Mündung der Arme einfach.

\section{Rhabdammina M. SARS 1869}

Gehäuse lose zementiert, gewöhnlich Sandkörner, kein Schlick. Gelegentlich sind Schwammnadeln oder anderes Fremdmaterial eingebaut. Im Innern dünne chitinöse Tapete. Bindungszement im allgemeinen gelblich-braun. Mündung einfach. In arktischen und subarktischen Gewässern weit verbreitet.

\section{Crithionina Goes 1894}

Gehäuse linsenförmig oder variierend. Nur eine Kammer. Wandung besteht aus kleinen Schwammnadeln und sehr feinem Sand bzw. Kalziumkarbonat, zart und zerbrechlich, mit wenig Bindemittel. Farbe Weiß bis Grau.

\section{Astrammina RhUmbler 1931}

Gehäuse frei, sphaerisch, eine einzige Kammer mit wenigen röhrenartigen Ausläufern. Sandschalig mit eingebauten Schwammnadeln, häufig auch Diatomeen. Mündungen sind die offenen Röhrchen. Unterscheidet sich von Astrorbiza durch einen globularen Zentralkörper (Astrorbiza $=$ linsenförmiger Zentralkörper) mit wenigen, armartigen Ausläufern.

\section{Rhizaminidae}

\section{Rhizammina BRADY 1879}

Gehäuse röhrenförmig, einfach oder dichotom. Wandung flexibel, chitinös. Nicht selten andere Foraminiferengehäuse mit eingebaut. Mündungen beiderseits der Röhre, einfach.

\section{Bathysiphon M. SARS 1872}

Gehäuse röhrenförmig, bis über $50 \mathrm{~mm}$ Länge. Gerade bis leicht gebogen. Im getrockneten Zustand z. T. eingerollt. Wandung besteht aus kleinen zerbrochenen Schwammnadeln, überdeckt mit feinem amorphen Material, nicht karbonatisch. Lose zementiert. Mündungen beiderseits der Röhre.

\section{Saccamminidae}

\section{Psammosphaera ScHuLze 1875}

Gehäuse kugelförmig, frei oder festgewachsen. Wandung aus Quarzkörnern, Schwammnadeln oder anderen Foraminiferengehäusen, selten Glimmerplättchen. Agglutiniert.

\section{Saccammina M. SARS 1869}

Gehäuse meistens frei, kugelig, mit einer schwach halsförmig ausgebildeten einfachen Mündung. Wandung Quarzkörner, Farbe Rotbraun bis Grau. 


\section{Proteonina WiLliamson 1858}

Gehäuse frei. Spindelförmige, ungeteilte Kammer. Wandung dünne Chitintapete mit Quarz- und Mineralkörnern zementiert. Mündung zirkulär mit kleinem Hals.

\section{Marsupulina RHUMBLER 1903}

Gehäuse frei, beutelförmig ellipsoid. Wandung mit feinem amorphen Kalzitmaterial. Mündung rund, an einer Seite, endständig. Meist in Flachwassergebieten lebend.

\section{Thurammina H. B. BRADY 1879}

Gehäuse frei, kugelig, mit papillenartigen Erhöhungen, in denen sich die Mündungen befinden. Wandung feines, amorphes Material. Farbe Grau bis Schmutzigweiß.

\section{Technitella NORMAN 1878}

Gehäuse länglich, oval bis walzenförmig. Wandung aus fast parallel liegenden Schwammnadeln. Mündung endständig, rund, manchmal mit einem kleinen Hals versehen.

\section{Pilulina W. B. CARPENTER 1870}

Gehäuse frei, rund bis oval. Wandung aus sehr feinem Spongienmaterial mit wenig Zement oder Sand. Mündung leicht gebördelt, länglich. Bevorzugt tiefes und kaltes Wasser.

\section{Armorella Heron-Allen \& Earland 1932}

Gehäuse frei, sphaerisch, eine einzige Kammer mit einer Anzahl röhrenförmiger Auswïchse, die verästelt sind. Wandung: unsortierte Quarzkörner - auch Diatomeen und Spongiennadeln werden verarbeitet - mit einem hellen zementartigen Bindemittel. Mündungen an den Enden der Röhren.

\section{Causia Rhumbler 1938}

Gehäuse: eine einzige Kammer, plankonvex, Dorsalseite konvex. Die Peripherie der Kammer bildet einen flachen, dünnen und breiten Kragen. Wandung keratinös, dünnwandig, mit mehr oder weniger feinem Mineralmehl. Mündung: ein kleines Loch an der Ventralseite.

\section{Reophacidae}

\section{Reophax MONTFort 1808}

Gehäuse: spindelförmig-kionisch, langgestreckt. Kammern gradlinig, dicht aufeinanderfolgend oder durch dünne Hälse miteinander verbunden. Meist rauhe Wandung durch grobes Material (Quarz, Minerale, vereinzelt Schwammnadeln oder andere Foraminiferenschalen verarbeitet). Fest verkittet. Mündung einfach, endständig, manchmal mit einem kleinen Hals. 
Ammodiscidae

\section{Ammodiscus Reuss 1861}

Gehäuse frei, planispiral gewunden. Wandung fein agglutiniert bis rein sekretorisch (tektinös bis kieselig). Mündung: offenes Ende der Spirale.

\section{Glomospira RzeHAK 1888}

Gehäuse knäuelartig, in verschiedenen Ebenen gewundene Kammern. Wandung fein agglutiniert. Farbe meist Rötlichbraun. Mündung in der letzten Kammerwindung, einfach, rund.

\section{Ammolagena EIMER \& FICKERT 1899}

Gehäuse sessil. Proloculus eiförmig, an der festsitzenden Seite abgeflacht, in eine zweite Kammer übergehend, diese ist röhrenförmig mit gleichbleibendem Durchmesser. Mündung stellt das Röhrenende dar. Farbe Gelb-Braun, fein agglutiniert.

\section{Lituolidae}

\section{Haplophragmoides CUSHMAN 1910}

Gehäuse frei planispiral, mit mehreren Windungen. Teilweise bis ganz involut. Menge des Bindungsmittels (Zement) stark schwankend. Agglutinierend, auch mit Fremdmaterial. Mündung einfach, rund oder spaltförmig am Ende der letzten Kammer.

\section{Recurvoides EARLAND 1934}

Gehäuse im Jugendstadium planispiral. Seine Achse steht in den späteren, auch planispiralen Windungen, fast senkrecht. Oft mit hervorragenden Mündungslippen. Mündung klein, eng, schlitzförmig.

\section{Cribrostomoides Cushman 1910}

Gehäuse ähnlich Haplophragmoides, doch die Mündung liegt etwas über der Basalnaht der letzten Kammer. Beim ausgewachsenen Exemplar zahnartige Vorsprünge in der Mündung, dadurch kann die Mündung in eine Reihe runder Offnungen umgewandelt werden.

\section{Ammobaculites Cushman 1910}

Gehäuse: im Jugendstadium mehr oder weniger planispiral, dann entrollt. Wandung einfach, agglutiniert. Mündung rundlich, terminal.

\section{Adercotryma Loeblich \& Tappan 1952}

Gehäuse frei, subglobular oder oval, länglich in Richtung der Windungsachse, leicht asymmetrisch. Mündung ist ein niedriger Schlitz oder bogenförmig seitlich des letzten Unganges. Unterscheidet sich von Haplophragmoides durch größere Länge der Achse zur Breite und die asymmetrisch angeordnete Mündung. 


\section{Ammotium Loeblich \& TAPpan 1953}

Gehäuse frei, abgeflacht, ovale Form. Kammern anfangs eingerollt, später entrollt. Die Kammerwände ziehen sich herunter bis zum spiralen Teil. Kammern evolut. Agglutinierend. Mündung einfach, rundlich, endständig.

\section{Textulariidae}

\section{Morulaeplecta HöGLund 1947}

Gehäuse klein, länglich-spindelförmig. Zwei- bis dreimal so lang wie breit. Initialende aufgebläht durch 6 oder 7 Kammern, die den Proloculus umschließen. Nachfolgender Teil ist biserial, bis zu 20 Kammern, subglobular, etwas zusammengedrückt. Grob agglutiniert. Oberfläche rauh. Kammernähte schlecht erkennbar. Farbe Grau-Weiß bis rötlich. Mündung wie bei Spiroplectammina.

\section{Textularia Defrance 1824}

Gehäuse anfangs spiraliges Stadium, dann biserial, seitlich komprimiert. Agglutiniert, Bindemittel kalkig, kieselig oder eisenhaltiger Zement. Im Innern dünne Tektintapete. Wandung perforiert. Mündung: ein länglicher Spalt an der Basalnaht der letzten Kammer.

\section{Siphotextularia Finlay 1939}

Gehäuse und Form wie bei Textularia meist quadrangular im Schnitt. Mündung in einer kleinen kurzen Röhre ("Sipho“).

\section{Bigenerina D'ORBIGNY 1826}

Anfangskammern biserial, dann übergehend in einen uniserialen Teil. Mündung im uniserialen Teil einfach, terminal. Im biserialen Teil wie bei Textularia. Agglutinierend.

\section{Verneuilinidae}

Verneuilina D'ORBIGNY 1840

Gehäuse triserial, im Querschnitt triangular. Jede Windung mit 3 Kammern. Mündung in Form eines niedrigen basalen Schlitzes (wie bei Textularia).

\section{Gaudryina D'OrBIGNy 1839}

Gehäuse anfangs triserial, dann in ein biseriales Stadium übergehend. Die Stärke der Agglutination und die Kammerform ist im biserialen Teil stark schwankend. (Letztere rund bis mehr oder weniger quadratisch.) Mündung ist meist endständig, in der letzten Kammer, am inneren Rand der Naht der vorhergehenden Kammer.

\section{Valvulinidae}

Gehäuse triserial, bei der megalosphärischen Form jedoch mit mehr als drei Kammern 
in einer Windung. Stark schwankend in der Agglutination. Mündung: deutlicher klappenförmiger Zahn.

\section{Eggerella Cushman 1933}

Im Jugendstadium der mikrosphaerischen Form mit fünf Kammern in einer Windung, später reduziert auf vier, in der Endwindung auf drei. Agglutinierend mit kalkigem Bindemittel oder fast feinkörnig-kalkig. Mündung: feiner Schlitz an der Basis der obersten Kammer.

\section{Dorotbia Plummer 1931}

Im Jugendstadium der mikrosphaerischen Form mit fünf bis sechs Kammern in einer Windung, jedoch schnelle Reduzierung auf drei, im Endstadium auf zwei Kammern. Agglutinierend bis körnig-kalkig. Mündung wie bei Eggerella.

\section{Liebusella Cushman 1933}

Vier bis fünf Anfangskammern in einer Windung (Umgang), schnell reduziert auf drei und dann auf eine Kammer. Kammerinneres „labyrinthisch“. Grobe Agglutination mit kalkigem Bindemittel. Mündung komplex oder unregelmäßig, manchmal mit kleinem Hals.

\section{Clavulina D'ORBIGNY 1826}

Gehäuse länglich, spindelförmig. Anfangs triserial, dann in einen uniserialen Teil übergehend. Mündung terminal in der Endkammer, mit einem Zähnchen versehen.

\section{Silicinidae}

\section{Miliammina Heron-ALIEN \& EARLANd 1930}

Gehäuse quinqueloculin bis irregulär triloculin, anfangs planispiral. Wandung fein agglutiniert. Mündung endständig, rundlich, oft mit einem Zahn.

\section{Miliolidae}

\section{Quinqueloculina D'ORBIGNY 1826}

Gehäuse in fünf Ebenen gewunden. Die Kammern haben die Länge einer halben Windung, in gegeneinander um $144^{\circ}$ gedrehten Ebenen wachsend. Fünf Kammern bilden im Querschnitt zwei Windungen. Mündung endständig, gerundet, mit einem typischen einfachen Zahn. Im Innern mit einer Tektintapete ausgekleidet. Außerlich porzellanartig bis mattweiß. Einige Arten mit agglutiniertem Material behaftet.

\section{Sigmoilina SCHLUMBERGER 1887}

Anfangskammern wie bei Quinqueloculina, die nächsten in mehr als $180^{\circ}$ gegeneinanderstehenden Ebenen wachsend. Gehäuse oft mit agglutiniertem Material behaftet. Mündung gerundet, mit einfachem Zahn. 


\section{Massilina SChlumberger 1893}

Anfangskammern quinqueloculin, spätere Kammern in einer Ebene wachsend. Schale häufig mit einem agglutinierenden Belag. Mündung einfach, mit typischem 2lappigen Zahn.

\section{Spiroloculina D'ORBIGNY 1826}

In der mikrosphaerischen Form Anfangskammer quinqueloculin. Bei der makrosphaerischen Form fehlend oder stark reduziert. Nachfolgende Kammern in einer Ebene, $1 / 2$ Windung lang. Schale manchmal mit agglutiniertem Belag. Mündung meist mit kleinem Hals und einfachem oder zweilappigem Zahn. Mündungsrand oft gebördelt.

\section{Miliolinella WIESNER 1931}

Gehäuse wie bei Quinqueloculina, aber hier die Mündung mit einem großen, flachen Zahn, der fast die ganze Mündung einnimmt.

\section{Ammomassilina Cushman 1933}

Anfangs quinqueloculin, später mehr als acht Kammern in einer Windung, die letzte in einer Ebene. Wandung überzogen mit dünner Lage von agglutiniertem Material. Mündung siebförmig.

\section{Triloculina D'ORBIGNY 1826}

Anfangs quinqueloculin, dann wachsen die Kammern um etwa $120^{\circ}$ gegeneinander gedrehte Ebenen, so daß äußerlich immer die drei letzten Kammern sichtbar sind. Schale variiert von porzellanartig, mattweiß bis gelegentlich mit agglutiniertem Belag. Mündung mit zweilappigem Zahn.

\section{Pyrgo Defrance 1824}

Quinqueloculines Anfangsstadium, dann folgt ein triloculines Stadium. Letzte Kammern gegeneinander um $180^{\circ}$ stehend, involut, so daß nur die zwei letzten Kammern sichtbar sind. Mündung rund, mit einem breiten, gegabelten Zahn.

\section{Pyrgoella Cushman \& WhITE 1936}

Gehäuse wie bei Pyrgo, allerdings schließt die letzte Kammer die vorhergehende bis auf einen schmalen Streifen ein. Mündung: triangularer Zahn, fast ganz die Mündungsöffnung füllend, etwa Y-förmig, bei einigen Arten in drei, vier oder mehr längliche, manchmal gewundene Offnungen übergehend.

\section{Biloculinella WIESNER 1931}

Gehäuse wie bei Pyrgo, aber mit breitem, flachen Zahn, der von der Basis der Mündung aus diese fast ganz ausfüllt.

\section{Ophthalmidiidae}

\section{Cyclogyra Wood 1842}

Gehäuse frei, discoidal, mit globularem Proloculus. Kammer gerundet, lang, ungeteilt und röhrenförmig. Planspiral, evolut aufgerollt. Unperforiert. Gehäuse aus $\mathrm{CaCO}_{3}$. 
Mündung bildet das offene Ende der letzten Kammerwindung. Mündungsrand manchmal mit einem dicken Wulst.

\section{Trochamminidae}

\section{Trochammina PARKER \& Jones 1859}

Gehäuse frei oder festwachsend. Trochoid-spiralig. Kammern flach bis stark aufgetrieben. Wandung sandig mit chitinöser Basis. Mündung auf der Umbilicalseite, schlitzförmig.

\section{Jadammina BARTENSTEIN \& BRAND 1938}

Gehäuse: kegel-spiralig, niedrig. Spiralseite flach. Kammern sichtbar. Nabelseite eingesenkt, nur die Kammern der letzten Windung erhöht. 8-10 Kammern in einem Umgang. Schwach S-förmig gebogene Kammernähte. An der Basis der Endkammer befindet sich ein Mündungsschlitz, darüber, auf der Stirnseite der Kammer, in halsartigen Fortsätzen drei bis sieben Mündungsöffnungen. Wandung: eine kalkfreie Pseudochitintapete, in die sehr kleine Quarzkörner vollkommen eingebettet sind. Kammern nach dem Trocknen häufig eingefallen.

\section{Lagenidae}

\section{Lenticulina LAMARCK 1804}

Gehäuse planispiral, meist involut, aber auch Ubergänge vom ursprünglich spiralen Teil zum entrollten Teil der letzten Kammern. Hierzu gehören: Astacolus MONTroRt 1808, Marginulinopsis Silvestri 1904, Vaginulinopsis Silvestri 1904, Saracenaria Defrance 1824, Planulina Defrance 1824. Kammern zahlreich, meist triangular in der Seitenansicht. Schale sehr fein perforiert, glasartig. Mündung strahlenförmig an der Stirnseite der Kammer am peripheralen Winkel. Die Strahlen sind alle annähernd gleich lang. Durch alle Obergänge, auch in der Mündungsform, ist Lenticulina mit Robulus MonTFORT 1808 verbunden.

\section{Nodosaria Lamarck 1812}

Geradlinige Anordnung der Kammern, bei der mikrosphärischen Form manchmal mit gebogenem Anfangsstadium. Kammernähte (Suturen) senkrecht zur Gehäuseachse. Kammern umfassend, aber auch mit langem Hals miteinander verbunden. Mündung an der Peripherie, strahlenförmig.

\section{Dentalina D'ORBIGNY 1826}

Kammern in einer gekrümmten Reihe angeordnet, zumindest im Jugendstadium. Mündung subterminal, strahlig. Durch Ubergänge mit Nodosaria und Marginulina verbunden.

\section{Lagena WALKER \& BoYs 1784}

Gehäuse einkammerig, oft stark skulptiert. Wandung fein bis grob perforiert. Mündung sowohl ohne als auch mit Hals. Mündung beträchtlich variierend: strahlenförmig (sel- 
ten), rund, elliptisch, schlitzförmig, endständig oder seitlich. Formen mit einer entosolenen Röhre gehören zur Familie Buliminidae. Hierzu auch Oolina D'Orbigny 1831, Ellipsolagena Silvestri 1923, von Oolina durch die abgeflachte Gestalt unterschieden. Aber hier gibt es eine große Variationsbreite, so daß eine Trennung der Gattungen sehr schwierig ist.

\section{Amphicoryne SCHLUMBERGER 1881}

Gehäuse in der Jugend gleich Lenticulina, die letzten Kammern haben die Form einer Nodosaria mit aufgeblähten Kammern. Fein perforiert.

\section{Pseudonodosaria BoomgaArt 1949}

Gehäuse frei, uniserial und durchaus gradlinige Kammern, stark umfassend im Anfangsteil, nachfolgende Kammern können aufgebläht und weniger umfassend sein. Suturen horizontal.

\section{Polymorphinidae}

\section{Guttulina D'ORBIGNY 1839}

Die Kammern sind im Querschnitt quinqueloculin angeordnet, in um $144^{\circ}$ gegeneinander geneigten Ebenen wachsend, wobei sie sich von der Gehäusespitze immer mehr entfernen. Mündung strahlenförmig.

\section{Pseudopolymorphina CusHMAN \& OZAWA 1928}

Form langgestreckt, gewöhnlich etwas gepreßt. Anfangskammer quinqueloculin, später biserial werdend. Leicht überlappend. Mündung endständig, strahlig. Oft ist die Art mit einer fistulösen Kammer umgeben. Weiß, fein perforiert.

\section{Globulina D'Orbigny 1839}

Gehäuse kugelig oder länglich, manchmal seitlich leicht gepreßt. Kammern in einer quinqueloculinen Reihe angeordnet, doch so übereinanderwachsend, daß das Gehäuse äußerlich triloculin erscheint. Kammernähte nicht eingesenkt. Porzellanartig bis glasartig. Fein perforiert.

\section{Glandulina D'OrBIGNY 1826}

Anfangsteil, mindestens bei der mikrosphärischen Form, biserial, sonst uniserial mit stark sich überlappenden Kammern. Porzellanartig. Mündung strahlig.

\section{Pyrulina D'OrbignY 1839}

Gehäuse länglich oder spindelförmig, Kammern anfangs triloculin, später biserial. Bei der mikrosphärischen Form anfangs quinqueloculin.

\section{Sigmomorphina Cushman \& Ozawa 1928}

Gehäuse seitlich abgeflacht. Die nachfolgenden Kammern voneinander um mehr als $144^{\circ}$, aber um weniger als $180^{\circ}$ geneigt, so daß im Querschnitt eine sigmoidale Serie gebildet wird. 
Polymorphina D'ORBIGNY 1826

Gehäuse breit und gepreßt. Anfangskammern sigmoidal, dann biserial.

Nonionidae

Nonion MonTfort 1808

Gehäuse planispiral, mehr oder weniger involut, bilaterial-symmetrisch. Peripherie breit, gerundet bis scharfkielig. Wandung fein bis grob perforiert. Mündung: ein schmaler Schlitz auf der Basalnaht.

\section{Astrononion CusHMAN \& EDwARDs 1937}

Gehäuse planispiral, involut. Kammern zahlreich. Ober den Kammernähten liegen beiderseits röhrenförmige oder rhombische Komplementär-Kämmerchen. Diese sind zu einem sternförmigen Gebilde zusammengesetzt, welches sein Zentrum über dem Nabel hat. Die Mündung ist ein basaler Schlitz auf der Stirnseite, manchmal in eine Reihe rundlicher Offnungen geteilt. Die Mündung des Komplementär-Kämmerchens ist rundlich, am Distalende, oder länglich und liegt an der Hinterseite.

\section{Nonionella Cushman 1926}

Gehäuse niedrig, trochospiral. Spiralseite stark, Umbilicalseite völlig involut. Letzte Kammer stark asymmetrisch, auf der Umbilicalseite in einem Lappen ausgezogen, der den Nabel überdeckt. Mündung: schlitzförmig, an der Basis der Stirnseite.

\section{Elphidium MONTFORT 1808}

Gehäuse planispiral, involut. Kammernähte allgemein mit deutlichen Suturalbrïcken. Die Kanäle münden in die zwischen den Suturalbrücken gelegenen Gruben aus. Mündung liegt an der Basis der letzten Kammer, einfach, oder als eine Reihe rundlicher Öffnungen.

\section{Melonis DE MONTFORT 1808}

Gehäuse frei, Anfangsstadium leicht trochospiral. Im Erwachsenenstadium planspiral, symmetrisch und involut. Zweinabelig, Nabel tief eingesenkt. Peripherie breit gerundet. 9 bis 12, selten mehr Kammern pro Umgang.

\section{Florilus DE MONTFORT 1808}

Gehäuse frei, planspiral, kaum asymmetrisch, involut aber mit breiten, flachen Kammern, welche an Breite und Dicke auffallend schnell zunehmen. Der Rand ist gerundet bis eckig. Fein perforiert, körnige Struktur. Mündung ist eine enge, intermarginale, äquatoriale Offnung. Um den Nabel windet sich ein einziger spiraliger Umgang der Kammern.

\section{Nonionellina Voloshinova 1958}

Gehäuse frei, im Anfangsstadium trochospiral, später planspiral und involut. Kammern vergrößern sich schnell um einen tiefen Nabel herum. Fein perforiert, körnige Struktur. Mündung ist ein schmaler Schlitz an der Basis der Stirn der letzten Kammer. 


\section{Cribrononion ThalmanN 1947}

Gehäuse planspiral, bilateral symmetrisch, involut. Kammernähte mit Vertiefungen versehen, vom offenen zum inneren Septalkanal in Verbindung mit dem Spiralkanal an beiden Seiten der Nabelregion. Keine Kammervorsprünge, aber solide und unperforierte Septalbrücken können beobachtet werden. Mündung schlitzförmig oder eine Reihe Poren an der Basis der Stirnseite.

\section{Elpbidiella Cushman 1936}

Unterscheidet sich von Elphidium durch zwei Offnungsreihen an den Suturen und durch Fehlen von Suturalbrücken.

\section{Cribroelphidium Cushman \& BRONNIMANN 1948}

Unterscheidet sich von Elphidium durch eine siebförmige Mündung bzw. Übergänge von basalen zu siebförmigen Mündungen.

\section{Buliminidae}

\section{Buliminella Cushman 1911}

Gehäuse: 3 oder mehr Kammern in einer Windung. Form oval bis spindelförmig, länglich gestreckt. Fein perforiert. Mündung: länglich, tränenförmig, in der Stirnwand gekrümmt auslaufend.

\section{Robertina D'ORBIGNY 1846}

Gehäuse in einer hohen Spirale gewunden, mit mehreren Kammern in einer Windung. Schale sehr fein perforiert. Mündung basal, tränenförmiger Schlitz an der Stirnseite. Eine akzessorische Mündung an der gegenüberliegenden Seite als dreieckige Offnung an der Stelle, wo die Kammernaht $z$ wischen den beiden. Teilen der letzten Kammer die vorletzte Kammer erreicht. Mit den beiden Mündungen steht eine innere, aus dünnen Lamellen gebildete Struktur in Verbindung.

\section{Robertinoides HögLuND 1947}

Gehäuse ähnlich der Robertina, doch besteht die Hauptmündung aus zwei divergierenden langen Schlitzen, die von der Basalnaht in die Aperturalwand verlaufen. Mit dieser komplizierten Mündung steht auch die innere Struktur in Zusammenhang, die komplizierter ist als bei Robertina.

\section{Bulimina D'OrBIGNY 1826}

Gehäuse länglich spiral, drei Kammern in einer Windung. Kammern gebläht, fein perforiert. Mündung mit innerer Zahnplatte, die bis zur vorhergehenden Mündung verläuft.

\section{Globobulimina CusHMaN 1927}

Gehäuse spiralig, triserial, mit stark involuten Kammern, so daß die drei letzten gewöhnlich die gesamte Oberfläche einnehmen. Mündung leicht gebördelt, mit einem Zahn oder Plättchen. 


\section{Virgulina D'ORBIGNY 1826}

Gehäuse länglich, spindelförmig, seitlich etwas gepreßt. Anfangs triserial, Endteil biserial, oft etwas unregelmäßig. Gehäuse in der Längsachse etwas gedreht. Fein perforiert. Mündung länglich, schlingenförmig, mit einem Zahn oder Zahnplättchen.

\section{Bolivina D'OrBIGNY 1839}

Kammern biserial angeordnet, Gehäuse zuweilen wenig um die Längsachse gedreht. Mündung virgulin, oft mit Zahn, der mit einer Zahnplatte in Verbindung steht. Wandung fein bis grob perforiert.

\section{Uvigerina D'ORBIGNY 1826}

Gehäuse triserial, spindelförmig gestreckt. Im Querschnitt rund. Kammern gebläht, perforiert. Mündung endständig, rund, mit einem gebördelten Rand. Häufig mit einem Zahn und Zahnplättchen.

\section{Rectobolivina Cushman 1927}

Gehäuse länglich, zylindrisch, leicht abgeflacht. Anfangskammern biserial, später uniserial. Fein perforiert, Mündung endständig, rund bis länglich, mit innerer, spiralig gedrehter Zahnplatte. Wandung glatt, knotig oder häufig Längsrippen.

\section{Stainforthia HoFker 1956}

Radial gebaute Virgulinen, schmal, langgestreckt, anfangs triserial, am wenigsten in der mikrosphärischen Generation, später biserial gewunden. Sonst wie bei Virgulina.

\section{Trifarina Cushman 1923}

Gehäuse länglich, triangular im Querschnitt. Anfangskammern in unregelmäßiger Spirale oder triserial. Endteil uniserial. Mündung terminal, mit Halsröhre und Lippe. Gehäuse perforiert.

\section{Sigmavirgulina LoEBLICH \& TAPPAN 1957}

In sich zur Längsachse um mehr als $180^{\circ}$ gedrehte Bolivina.

\section{Brizalina Costa 1856}

Gehäuse langgestreckt, verschmälert zulaufend. Gewöhnlich zusammengedrückt und lateral scharf gekielt. Fehlen der basalen gelappten Kammern (s. Bolivina). Mündung wie bei Bolivina mit Zahnplatte.

\section{Praeglobobulimina HoFker 1951}

Gehäuse frei, länglich, triserial mit stark überlappenden Kammern. In der Struktur radial perforiert. Mündung länglich von der Basis der letzten Kammer bis zum Gipfelpunkt. Innere Zahnplatte; freistehende, geneigte Lippe. Sonst wie Globobulimina.

\section{Stilostomella GuPPY 1894}

Gehäuse uniserial, gradlinig oder der Längsachse nach etwas gekrümmt. Mündung terminal, nierenförmig oder rundlich, mit kleinem gebördeltem Rand, häufig mit innerem Zahn. 


\section{Oolina D'ORBIGNY 1839}

Gehäuse einkammerig, mit kreisrundem bis ovalem Querschnitt, selten etwas asymmetrisch. Runde Mündung, terminal mit entosolenem Röhrchen; Mündung meist mit strahlenförmigen kleinen Schlitzen. Oberfläche glatt, gerieft, berippt, bestachelt oder ornamentiert.

\section{Fissurina Reuss 1850}

Gehäuse einkammerig, flach. Häufig randgekielt. Mündung terminal, meist schlitzförmig, zuweilen oval oder rund. Entosolene Röhre. Oberfläche wie bei Oolina.

\section{Parafissurina PARR 1947}

Gehäuse wie bei Fissurina. Mündung aber hier schlitz- oder sichelförmig an einer Seite, dicht am Rande des Gehäuses, mit entosolener Röhre.

\section{Rotaliidae}

\section{Spirillina Ehrenberg 1843}

Gehäuse aus Proloculus und planspiral gewundener Zweitkammer bestehend. Mit feiner bis grober Perforierung. Wandung kalkig. Mündung am offenen Röhrenende.

\section{Patellina Williamson 1858}

Gehäuse trochospiral. Zwei Kammern in jeder Windung, die periodisch wachsen, wobei die Segmente nicht durch Septen geteilt sind, sondern die langen, sackförmigen Kammern durch engere, U-förmig gebogene Röhren abgetrennt sind. Wandung kalzit, perforiert. Mündung an der Ventralseite.

\section{Discorbis Lamarck 1804}

Gehäuse plankonvex, mit flachgewölbter Spiralseite. Wandung grob perforiert. Mündung an der Ventralseite, vom Nabel bis über die scharfe Peripherie reichend, mit deutlicher Lippe.

\section{Gyroidina D'ORBIGNY 1826}

Gehäuse trochoid. Umbilicalseite oft stark konvex, involut, mit kleinem, tiefen Nabel. Spiralseite schwach konkav bis schwach konvex. Oberfläche glatt, porzellanartig. Mündung schlitzförmig zwischen Nabel und Peripherie.

\section{Eponides MONTFORT 1808}

Gehäuse trochoid und bikonvex. Nabel gefüllt mit hyalinem Material. Mündung auf der Basalnaht als Schlitz zwischen der Peripherie und dem Nabel, meist diesem näher liegend.

\section{Rotalia LAMARCK 1804}

Gehäuse: Dorsalseite evolut, Ventralseite involut. Nabelhöhlen fehlen. Kammerwände der Dorsalseite meist erhaben. Ventralseite tief eingesenkt mit seitlichen kleinen Spal- 
ten. Auf der Ventralseite unter den Kammern verläuft ein „Spiralkanal“, der mit den Kammern durch Nebenkanäle verbunden ist. Mündung an der Ventralseite zwischen der Außenseite und dem Umbilicalteil.

\section{Ammonia BRÜNNICH 1772}

Unterscheidet sich von Rotalia durch offene Umbilikalspalten und fehlenden Umm bilikalkanal.

\section{Rosalina D'ORBIGNy 1826}

Gehäuse plankonvex. Alle Windungen der Spiralseite sichtbar. Umbilikalseite flach, involut. Perforierung der Spiralseite grob, der Umbilikalseite fein. Schlitzförmige Mündung unter dem lobaten Rand der letzten Kammer auf der Umbilikalseite.

\section{Discorbinella Cushman \& MARTin 1935}

Gehäuse frei, plankonvex, stark zusammengepreßt. Spiralseite konvex, fast involut, nur ein kleiner Teil des vorhergehenden Umganges im Zentrum sichtbar. Umbilikalseite flach bis leicht konkav, genabelt, aber fast involut. Rand scharf gekielt. Mündung an der Umbilikalseite nahe der Peripherie mit zusätzlicher Offnung am entgegengesetzten Rand der umbilikalen Kammervorwölbung.

\section{Neoconorbina Hofker 1951}

Gehäuse frei, trochospiral, konisch, konkav-konvex. Rand scharf winklig, gekielt. Anfangskammern subglobular, an der Spiralseite schnell in der Breite zunehmend, so daß die letzte Kammer über $3 / 4$ der Peripherie einnimmt und sehr viel breiter als hoch ist. Letzte Kammern an der Umbilikalseite mit ausgeprägter Vorwölbung im Zentrum, $z$. T. die zentrale Mündung überdeckend, so daß 2 Mündungen in Verbindung mit der vorletzten Kammer in Erscheinung treten. Beiderseits grob perforiert.

\section{Gyrodinoides BroTzEN 1942}

Gehäuse frei trochospiral, Spiralseite flachgedrückt, Umbilikalseite erhaben. Rand gerundet. Kammern im Schnitt rhombisch. Kammernähte radial bis geschwungen, flach. Beidseitig perforiert.

\section{Planspirillina Bermudez 1952}

Gehäuse frei, planspiral, Peripherie gerundet bis gestutzt. Alle Windungen sichtbar auf der Spiralseite. Ventralseite: letzte Windung sichtbar, andere Windungen bedeckt mit Knötchen oder Pusteln aus durchsichtigem Kalzit. Dorsalseite grob, Ventralseite fein perforiert. Mündung bildet das offene Ende der Röhre.

\section{Cassidulinidae}

\section{Cassidulina D'ORBIGNY 1826}

Gehäuse bikonvex oder subglobular, auch planspiral gewunden. Umgänge aus zwei alternierenden Kammerreihen zusammengesetzt, gewöhnlich involut. Mündung schlitz- 
förmig in die Stirnwand auslaufend, manchmal mit flachem Zahn. Fein perforierte Schale, porzellanartig bis glasklar.

\section{Cassidulinoides Cushman 1927}

Gehäuse: Anfangsstadium wie bei Cassidulina. Endstadium entrollt, gradlinig, mit alternierenden Kammern. Mündung terminal, spaltartig.

\section{Globocassidulina Voloshinova 1960}

Gehäuse frei, subglobular. Gerundeter peripheraler Rand. Nabel geschlossen. Kammern biserial und eingerollt. Fein perforiert, Oberfläche gewöhnlich glatt. Mündung ist ein kleiner Schlitz in der Mitte der letzten Kammer. Stirnseite mit gefaltetem Saum, keine Mündungs-Zahnplatte.

\section{Islandiella Nørvang 1958}

Gehäuse frei, linsenförmig bis subglobular. Rand gerundet, Nabel verschlossen. Kammern sind biserial angeordnet, planspiral eingerollt.

\section{Chilostomellidae}

\section{Chilostomella Reuss 1850}

Gehäuse zylindrisch bis oval. Ahnenstadium allomorphinoid, Endteil biserial, mit umfassenden, stark aufgeblähten Kammern. Mündung auf der Basalnaht, schlitzförmig, bogenartig.

\section{Pullenia PARKer \& Jones 1862}

Gehäuse planispiral, involut, mit wenigen Kammern in der letzten Windung. Mündung auf der Basis der Stirnseite der letzten Kammer, flach, lang und bogenförmig.

\section{Sphaeroidina D'ORBIGNY 1826}

Gehäuse aus halbkugeligen, irregulären Kammern zusammengesetzt. Schale fein perforiert. Mündung an der Basalnaht, bogenförmig, mit flachem Zahn.

\section{Globigerinidae}

\section{Globigerina D'ORBIGNY 1826}

Gehäuse trochospiral, im Anfangsstadium oft abgeflacht, discorbisähnlich, später mit aufgeblähten, kugeligen bis ovalen Kammern. Wandung dick, mit kleinen Dellen (in denen im lebenden Stadium dünne, lange Stacheln sitzen). Mündung groß, bogenförmig, manchmal mit Lippe. Planktische Lebensweise.

\section{Orbulina D'ORBIGNY 1839}

Gehäuse im Jugendstadium ähnlich Globigerina. Letzte Kammer beim erwachsenen Exemplar kugelig, das Jugendstadium meist völlig, seltener fast ganz einschließend. 
(Höchste Form der Anpassung an die planktische Lebensweise.) Keine Mündung, das Protoplasma dringt durch grobe Poren nach außen. Oberfläche wie bei Globigerina. Planktische Lebensweise.

\title{
Anomalinidae
}

Anomalina D'ORBIGNY 1826

Gehäuse in der Jugend trochoid, im erwachsenen Zustand beiderseits stark, aber nicht gleichmäßig involut, mit der Neigung zu planspiraler Windung. Peripherie gerundet. Mündung basal, auf den peripheralen Teil begrenzt. Wandung meist grob perforiert.

\section{Paromalina Loeblich \& TAPPAN 1957}

Gehäuse frei, planspiral, beidseitiger Nabel, im Zentrum etwas eingedrückt. Rand abgestutzt. Die Kammern bedecken mit der Nabelseite die Kammernähte und z. T. die Kammern der vorhergehenden Kammernwindungen. Nähte radial, eingesenkt. Schale an den Seiten nahe der Peripherie und an der Stirnseite unperforiert und durchscheinend, glasartig. Ubriges Gehäuse grob perforiert. Mündung an der Basis der letzten Kammer spaltenförmig, setzt sich von der Peripherie längs der Spiralnaht fort.

\section{Cibicides MontFort 1808}

Gehäuse plankonvex, gewöhnlich mit der planen Spiralseite aufgewachsen (auf Pflanzen, Steinen, Schill etc.). Nabelseite involut. Mündung schlitzförmig auf der Basalnaht, greift von der Spiralseite über die Peripherie auf die Nabelseite über. Meist grobporige Schale.

\section{Cibicidoides BROTZEN 1939}

Gehäuse freilebend, bikonvexe Form, sonst wie bei Cibicides.

\section{Dyocibicides Cushman \& Valentine 1930}

Gehäuse: Jugendstadium wie bei Cibicides, spätere Kammern biserial oder uniserial. Mündung terminal, länglich, mit Lippe.

\section{Cibicidella Cushman 1927}

Gehäuse festwachsend. Jugendform wie bei Cibicides. Im Endstadium mit unregelmäßig wachsenden Kammern. Mündungen z. T. an mehreren Kammern der letzten Windung, rundlich, mit kurzem Hals und gebördeltem Rand.

\author{
Planorbulinidae
}

\section{Planorbulina D'ORBIGNY 1826}

Anfangsstadium trochoid, mit der Spiralseite festwachsend. Nachfolgende Kammern auf der Peripherie wachsend, ziemlich unregelmäßig an Größe und Gestalt. Die Kammern der Endstadien haben meist zwei distal gelegene Mündungen. 


\section{Acervulina Schultze 1854}

Gehäuse festsitzend. Anfangsteil spiralgewunden, nachfolgende Kammern bilden eine unregelmäßige Anhäufung. Große Wandperforierungen bilden Mündungen.

\section{Gypsina CARTER 1877}

Gehäuse sphaerisch, eine große Anzahl unregelmäßiger Kammern. Anfangskammern sitzen auf einem Fremdkörper, die später folgenden Kammern umschließen diesen zu einer sphaerischen Form. Mündungen sind große Poren im Gehäuse.

\section{ZUSAMMENFASSUNG}

1. Die am weitesten verbreiteten Gewinnungsmethoden für Foraminiferen werden beschrieben.

2. Die in der Nordsee vorkommenden Foraminiferen werden dargestellt und - ergänzt durch eine taxonomische Ubersicht - kurz charakterisiert.

3. Übersichtskarten zeigen Häufigkeit und Verteilung der Foraminiferen in der Nordsee.

Danksagungen: Ich danke Herrn Dr. K. FigGe, Hamburg, für seine Unterstützung bei der Abfassung dieser Arbeit. Herrn Prof. Dr. K. Vollbrecht, Hamburg, danke ich für anregende Diskussionen und Hinweise.

\section{ZITIERTE LITERATUR}

Ergänzt durch wichtigste Bestimmungsliteratur und Nachschlagewerke

BARKER, R. W., 1960. Taxonomic notes on the species figured by H. B. BRADY in his report on the Foraminifera dredged by H. M. S. "Challenger" during the years 1873-1876. Spec. Publs., Soc. econ. Palaeont. and Miner., Tulsa, $\mathbf{9}$.

Bé, A. W. H., 1960. Some observations on Arctic planctonic Foraminifera. Contr. Cushman Foundation 11, 64-68.

Brady, H. B., 1884. Report on the Foraminifera dredged by H. M. S. "Challenger" during the years 1873-1876. Rep. scient. Results Voyage HMS "Challenger" (5: Zool.) 9, 1-814.

Cushman, J. A., 1918/31. The Foraminifera of the Atlantic ocean. Bull. U.S. natn. Mus. 104, $1-1064$.

- 1948. Arctic Foraminifera. Spec. Pub1. Cushman Lab. 23, 1-79.

- 1949. Recent Belgian Foraminifera. Mém. Inst. r. Sci. nat. Belg. 111, 1-59.

- 1950. Foraminifera, their classification and economic use. 4th ed., rev. and enl, with an illustr. key to the genera. Harvard Univ. Press, Cambridge, Mass., 605 pp.

Goes, A., 1894. A synopsis of the Arctic and Scandinavian recent marine Foraminifera hitherto discovered. K. svenska VetenskAkad. Handl. 25, 1-127.

Greil, K. G., 1968. Protozoologie. Springer, Berlin, Göttingen, Heidelberg. 2. Aufl., 511 pp.

Höglund, H., 1947. Foraminifera in the Gullmar Fjord and the Skagerak. Zool. Bidr. Upps. 26, $1-311$.

JARKE, J., 1960. Beitrag zur Kenntnis der Foraminiferenfauna der mittleren und westlichen Barents-See. Int. Rev. ges. Hydrobiol. 45, 581-654.

- 1961. Die Beziehungen zwischen hydrographischen Verhältnissen, Faziesentwicklung und Foraminiferenverbreitung in der heutigen Nordsee als Vorbild für die Verhältnisse während der Miocän-Zeit. Meyniana 10, 21-36. 
Loeblich, A. R. JR. \& Tappan, H., 1953. Studies of Arctic Foraminifera. Smithson. misc. Collns. 7 (4105), 1-150.

LuTZE, G. F., 1965. Zur Foraminiferenfauna der Ostsee. Meyniana 15, 75-142.

Moore, R. C. (Ed.), 1964. Treatise on invertebrate paleontology. Pt. C. Protista 2. Vol. 1.2. Univ. of Kansas Press, Lawrence, Kans.

Müller, A. H., 1958. Lehrbuch der Paläozoologie. Bd 2. T. 1. Protozoa, Mollusca. 1. VEB G. Fischer, Jena, $566 \mathrm{pp}$.

Phleger, F. B., 1960. Ecology and distribution of recent Foraminifera. Johns Hopkins Press, Baltimore, Md., 297 pp.

- Parker, F. L. \& Peirson, J. F., 1953. North Atlantic Foraminifera. Rep. Swed. deep Sea Exp. 7, 1-122.

Pokorny, V., 1958. Grundzüge der zoologischen Mikropaläontologie. 1. VEB Dt. Verl. d. Wissenschaften, Berlin, $582 \mathrm{pp}$.

Pratje, O., 1931. Die Sedimente der deutschen Bucht. Eine regional-statistische Untersuchung. Wiss. Meeresunters. (Abt. Helgoland) 18, 1-126.

Rhumbler, L., 1938. Foraminiferen aus dem Meeressand von Helgoland, gesammelt von A. Remane (Kiel). Kieler Meeresforsch. 2, 157-222.

Sснотт, W., 1966. Foraminiferenfauna und Stratigraphie der Tiefsee-Sedimente im Nordatlantischen Ozean. Rep. Swed. deep Sea Exped. 7, 357-469.

Thalmann, H. E., 1932. Nomenclator (Um- und Neubenennungen) zu den Tafeln 1 bis 115 in H. B. Bradys Werk über die Foraminiferen der Challenger-Expedition, London 1884. Eclog. geol. Helv. 25, 293-312.

Williamson, W. C., 1858. On the recent Foraminifera of Great Britain. The Royal Society, London, $107 \mathrm{pp}$.

Anschrift des Autors: B. GabeL

Deutsches Hydrographisches Institut

2 Hamburg 4

Bernhard-Nocht-Straße 78

Bundesrepublik Deutschland 


\section{Tafel 1}

1 Astrorbiza limicola SANDAHL (4:1): vom Fladengrund

2 Astrorbiza limicola SANDAHL (4:1): südlich von Helgoland

3 Astrorbiza arenaria NoRMan $(5: 1)$

4 Astrorhiza (Psammosiphonella) crassatina BRADY (6:1)

5,6 Rhabdammina discreta Brady $(6: 1)$ (nach Höglund)

7, 8 Rhabdammina scabra HögLund (3:1)

9 Rhabdammina abyssorum M. SARS $(5: 1)$

10,11 Rhabdammina abyssortm M. SARS (10:1): Fragmente

12,13 Rbabdammina discreta BRADY (10:1)

14 Rhabdammina sp. I $(12: 1)$ : häufig im Fladengrund

15 Rhabdammina sp. II $(12: 1)$ : häufig in der Doggerbank

16, 17 Critbionina pistm GoEs $(12: 1)(17=$ Querschnitt $)$

18 Crithionina granum GoEs (10:1)

19 Rhizammina indivisa BRADY (15:1)

20 Rbizammina algaeformis $\mathrm{BRADY}_{\mathrm{R}}(25: 1)$

21 Bathysiphon argenteus Heron-Allen \& EARLAND $(60: 1)$ 


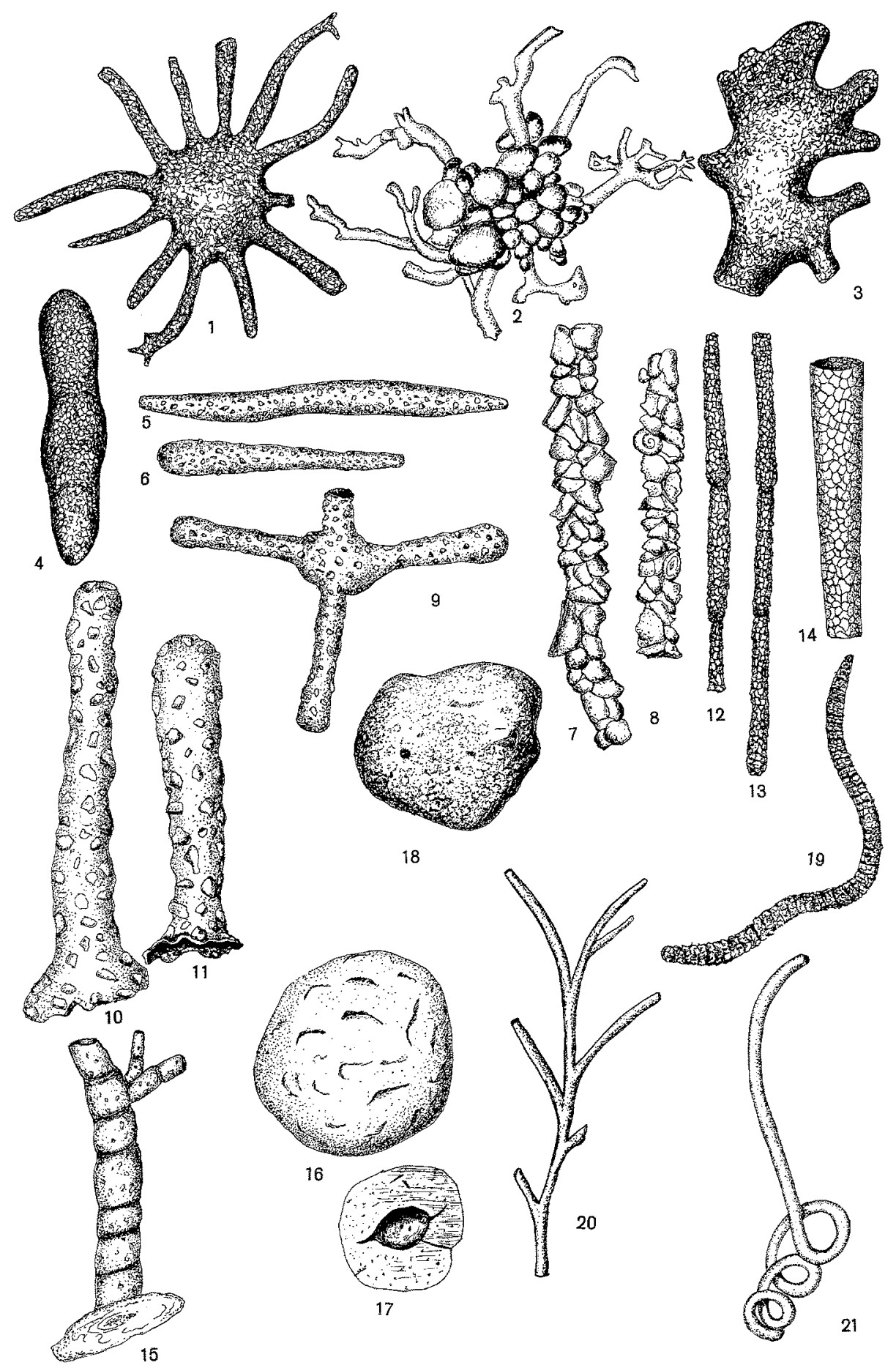

Tafel 1 


\section{Tafel 2}

1, 2 Psammosphaera fusca Schulze (20:1)

3 Saccammina sphaerica M. SARs (20:1)

4- 6 Psammosphaera exigua (RHUMBLER) (75:1): eingetrocknet, sonst kugelförmig

7 Reophax diffugiformis BRADX (50:1) (Proteonina) alt

8 Reophax fusiformis (WILliavson) $(62,5: 1)$

9 Reophax micacea (Cushman) $(50: 1)$

10, 11 Marsupulina schultzei RHUMBLER (50:1)

12, 13 Thurammina sphaerica HögLUnd $(100: 1)$

14 Technitella legumen Norman $(50: 1)$

15 Astrammina sphaerica (Heron-AlLen \& Earland) $(60: 1)$

16 Pilulina argentea Höglund $(100: 1)$

17 Hyperammina laevigata WrughT (10:1)

18, 19 Reophax nana Rhumbler (90:1)

20 Reophax regularis Höglund (30:1)

21, 22 Reophax subfusiformis EARLAND (30:1)

23 Reopbax scorpiurus Montfort $(30: 1)$

24 Reophax guttifer Brady $(60: 1)$

25 Reophax rostrata Höglund (30:1)

26 Reophax dentaliniformis BRADY (40:1)

27,28 Reophax catella HögLund (150:1) 


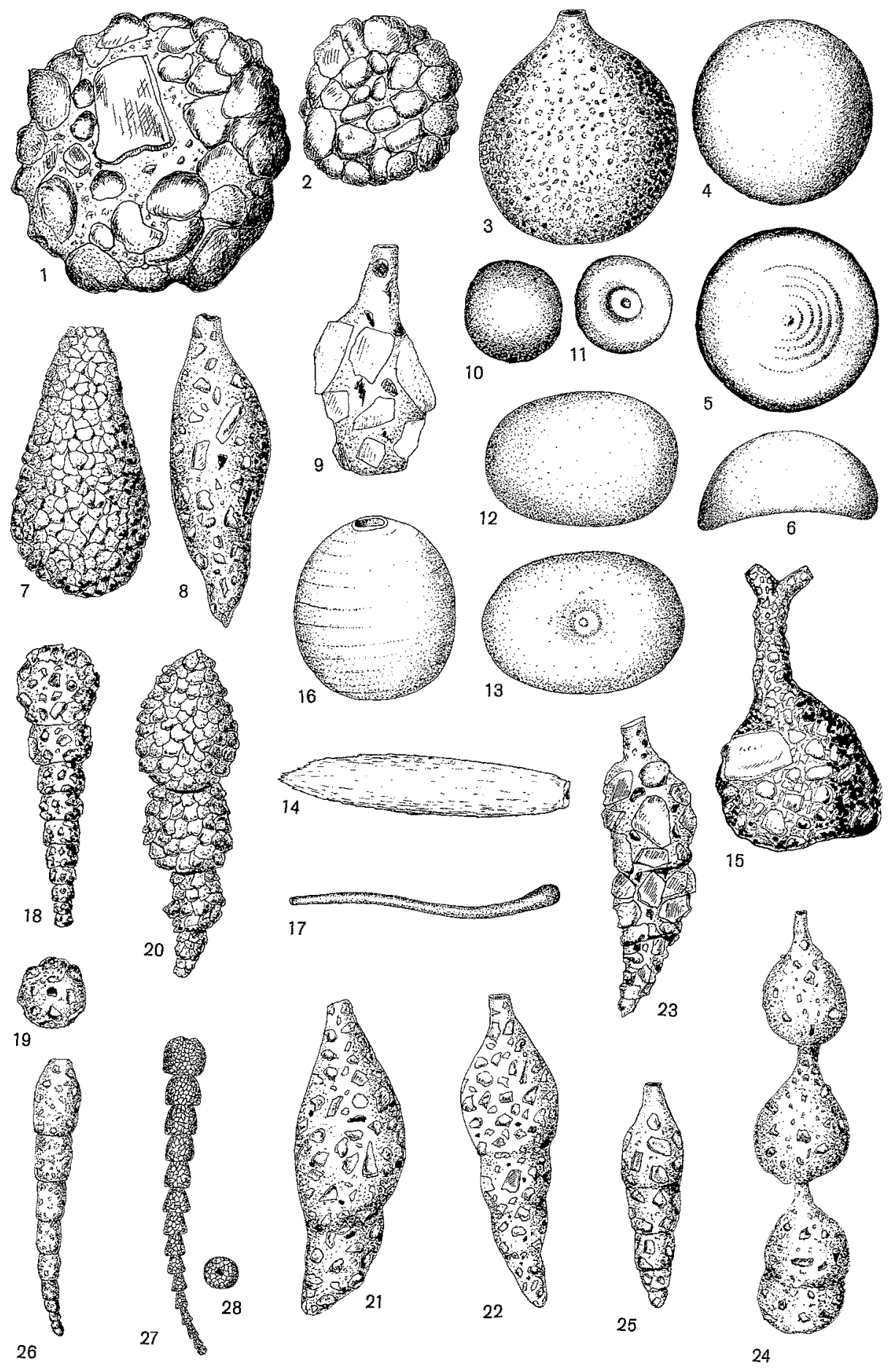

Tafel 2 


\section{Tafel 3}

1 Reophax nodulosus Brady $(10: 1)$

2 Reophax gracilis KIÄR $(40: 1)$

3 Reophax scotti CHASTER (40:1)

4 Reopbax catenata Höglund $(60: 1)$

5, 6 Ammodiscus planorbis HögLUND (75:1): mit Seitenansicht und Mündung

7, 8 Ammodiscus planus HögLUND $(75: 1)$

9, 10 Ammodiscus catinus Höglund $(75: 1)$

11,12 Ammodiscus minimus Höglund $(125: 1)$

13 Glomospira charoides (PARKER \& JONES) (45:1)

14 Glomospira charoides: Unterseite

15 Glomospira charoides: Seitenansicht

16 Ammolagena clavata (PARKER \& JoNES) (40:1)

17 Ammolagena clavata: Seitenansicht, aufgewachsen auf einem Muschelbruchstïck

18 Alveolophragmium wiesneri (PARR) $(50: 1)$

19 Alveolophragmium wiesneri: Seitenansicht

20 Haplophragmoides pusillum Höglund (150:1)

21 Haplophragmoides pusillum: Seitenansicht mit Mündung

22 Adercotryma glomerata (BRADY) $(100: 1)$

23 Adercotryma glomerata: Seitenansicht

24 Haplophragmoides membranaceum Höglund $(100: 1)$

25 Haplopbragmoides membranaceum: Seitenansicht mit Mündung

26,27 Discammina compressa (GoEs) (50:1)

28,29 Haplophragmoides canariensis (D’ORBIGNY) $(50: 1)$

30, 31 Haplopbragmoides bradyi ROBERTSON $(100: 1)$

32, 33 Recurvoides laevigatum HögLund $(80: 1)$

34,35 Cribrostomoides arctica (PARKER) $(75: 1)$

36, 37 Cribrostomoides wiesneri PARR (50:1)

38,39 Cribrostomoides jeffreysi (WrLliamson) $(60: 1)$ 
Foraminiferen der Nordsee
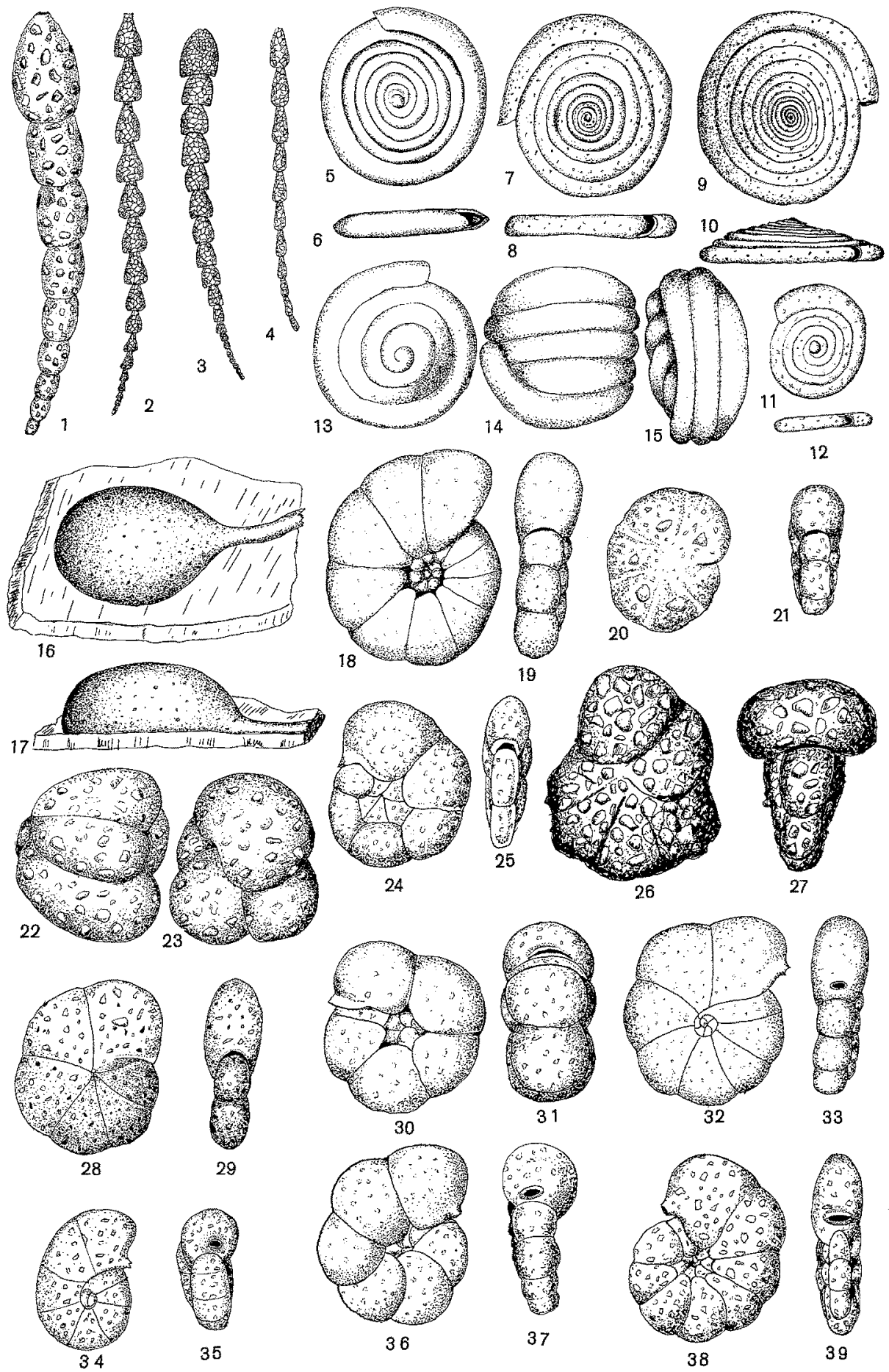

Tafel 3 


\section{Tafel 4}

1, 2 Cribrostomoides subglobosum (G. O. SARs) (30:1)

3, 4 Cribrostomoides crassimargo Norman $(25: 1)$

5,6 Cribrostomoides kosterensis HögLund $(75: 1)$

7, 8 Spiroplectammina biformis (PARKER \& JONES) (75:1)

9,10 Spiroplectammina wrightii (SIrvestRI) $(40: 1)$

11,12 Spiroplectammina sagittula (DEFRANCE) $(30: 1)$

13-15 Spiroplectammina sp. (75:1): aus dem Skagerrak

16,17 Morulaeplecta bulbosa Höglund (30:1)

18,19 Textularia cocbleata LACROIX (100:1)

20,21 T'extularia truncata Höglund $(30: 1)$

22-24 Textularia bocki Höglund $(50: 1)$

25-27 Textularia skagerakensis Höglund $(75: 1)$

28-30 Textularia agglutinans D'ORBIGNY $(25: 1)$

31,32 Textularia conica D'ORRIGNY $(35: 1)$

33, 34 Textularia earlandi PARKeR (75:1)

35,36 Textularia gracillima Höglund $(75: 1)$

37, 38 Textularia tenuissima Earland $(75: 1)$

39-41 Siphotextularia rolshauseni (PhLeger \& Parker) (50:1)

42 Siphotextularia concava (KARRER) (50:1)

43-45 Ammobaculites agglutinans (D'ORBIGNY) $(75: 1)$

46-48 Bigenerina nodosaria D'ORBIGNY $(20: 1)$

49,50 Clavulina sp. $(75: 1)$

51-54 Verneuilina media Höglund $(50: 1)$

55-57 Verneuilina minuta WrESNER $(75: 1)$

58,59 Ammodiscus rbumbleri RoTTGART (50:1)

60,61 Causia injudicata RHUmbler $(75: 1)$ 


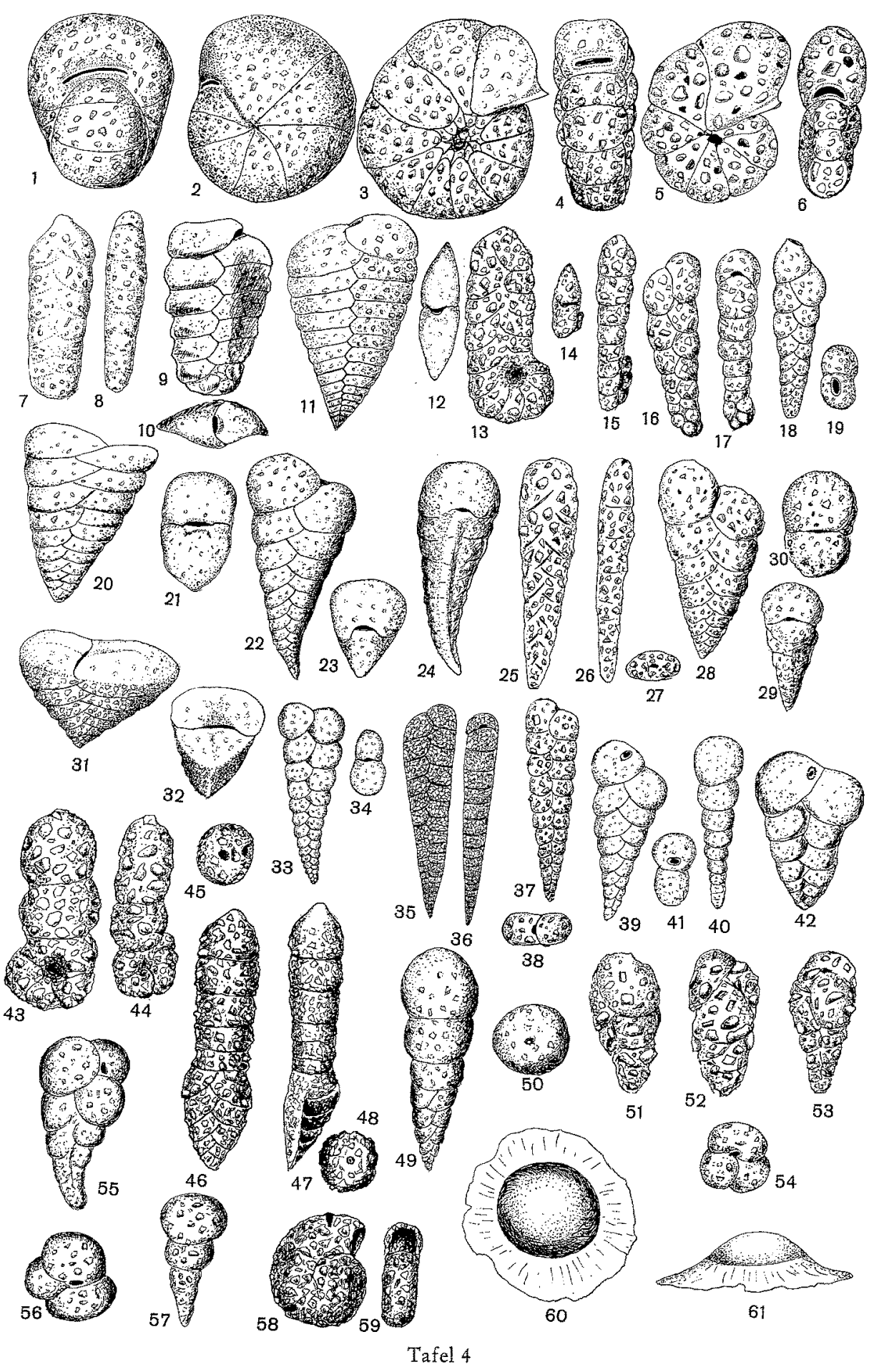




\section{Tafel 5}

1, 2 Gaudryina rudis Wright $(30: 1)$ : nahe Schottland und Irland

3- 5 Verneuilina advena CushMaN $(50: 1)$

6,7 Eggerella affixa (Cushman) $(50: 1)$

8-10 Eggerella scabra (Williamson) (50:1)

11, 12 Eggerella arctica Höglund $(40: 1)$

13, 14 Tritaxis conica (PARKer \& Jones) $(35: 1)$

15-17 Tritaxis fusca (Wrumamson) (40:1)

18,19 Dorothia psendoturris (CUSHMAN) $(25: 1)$

20, 21 Liebusella goesi HögLund $(20: 1)$

22-24 Miliammina fusca (BradX) $(50: 1)$

25,26 Miliammina arenacea (CHAPMAN) $(25: 1)$

27, 28 Sigmoilopsis schlumbergeri SILVESTRI (50:1)

29,30 Quinqueloculina lucida (KARRER) (50:1)

31,32 Quinqueloculina agglutinans D'ORBIGNY $(40: 1)$

33,34 Quinqueloculina lata TERQUEM $(30: 1)$

35-37 Quinqueloculina sp. aff. Q. stelligera Schlumberger (50:1)

38,39 Quinqueloculina amygdaloides (BRADY) $(65: 1)$

40-42 Quinqueloculina arctica CushMaN (65:1): nördliche Nordsee, selten

43-45 Quinqueloculina seminuium (LINNE) $(40: 1)$ 


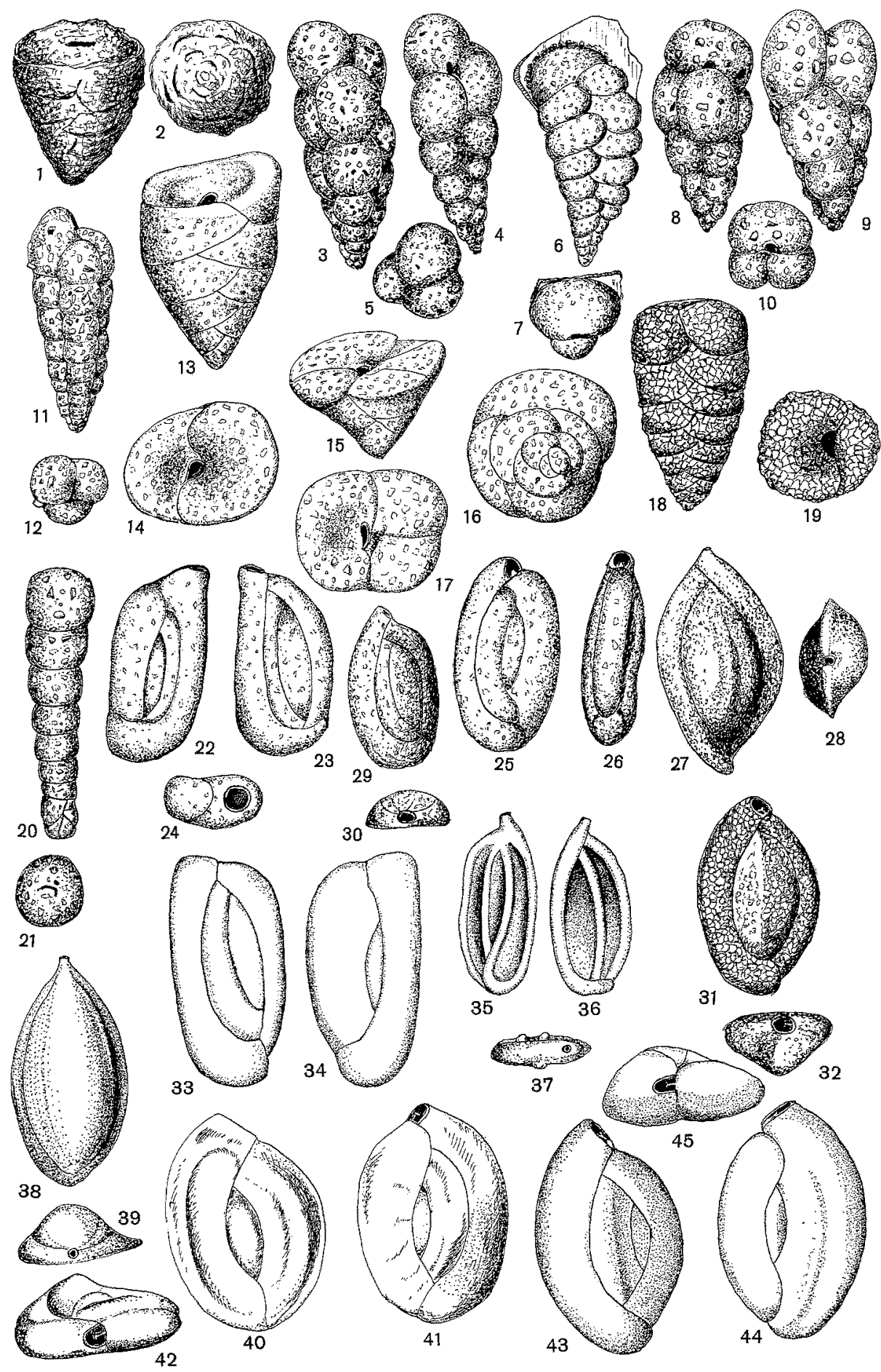

Tafel 5 


\section{Tafel 6}

1- 3 Quinqueloculina sp.cf. Q. vulgaris D'ORBIGNY $(25: 1)$

4, 5 Quinqueloculina sclerotica K.ARRER (40:1)

6,7 Quinqueloculina cliarensis Heron-ALLEN \& EARLAND (25:1)

8, 9 Quinqueloculina bicornis (WALKER \& BoYs) $(25: 1)$

10-12 Quinqueloculina cf. intricata TERQUEM (20:1)

13-15 Quinqueloculina sp. (20:1): Doggerbank

16, 17 Massilina annectens SChlumberger. (40:1)

18,19 Massilina secans D'ORBrGNY (40:1)

20, 21 Spiroloculina benbesti PETRI $(25: 1)$

Spiroloculina planulata LAMARCK: Eozän-Art

22-24 Spiroloculina depressa (D'ORBIGNY) $(25: 1)$

25,26 Spiroloculina grateloupi (D'ORBIGNY) $(25: 1)$

27, 28 Spiroloculina subimpressa PARR $(15: 1)$

29-31 Miliolinella meridionalis (D'ORBIGNY) $(30: 1)$

32-34 Miliolinella pratjense MEYER-ABICH $(40: 1)$

35-37 Miliolinella sp. (40:1): Braune Bank

38-40 Miliolinella subrotunda (MONTAGU) $(25: 1)$

41, 42 Ammomassilina asperula (KARReR) (40:1) 
Foraminiferen der Nordsee
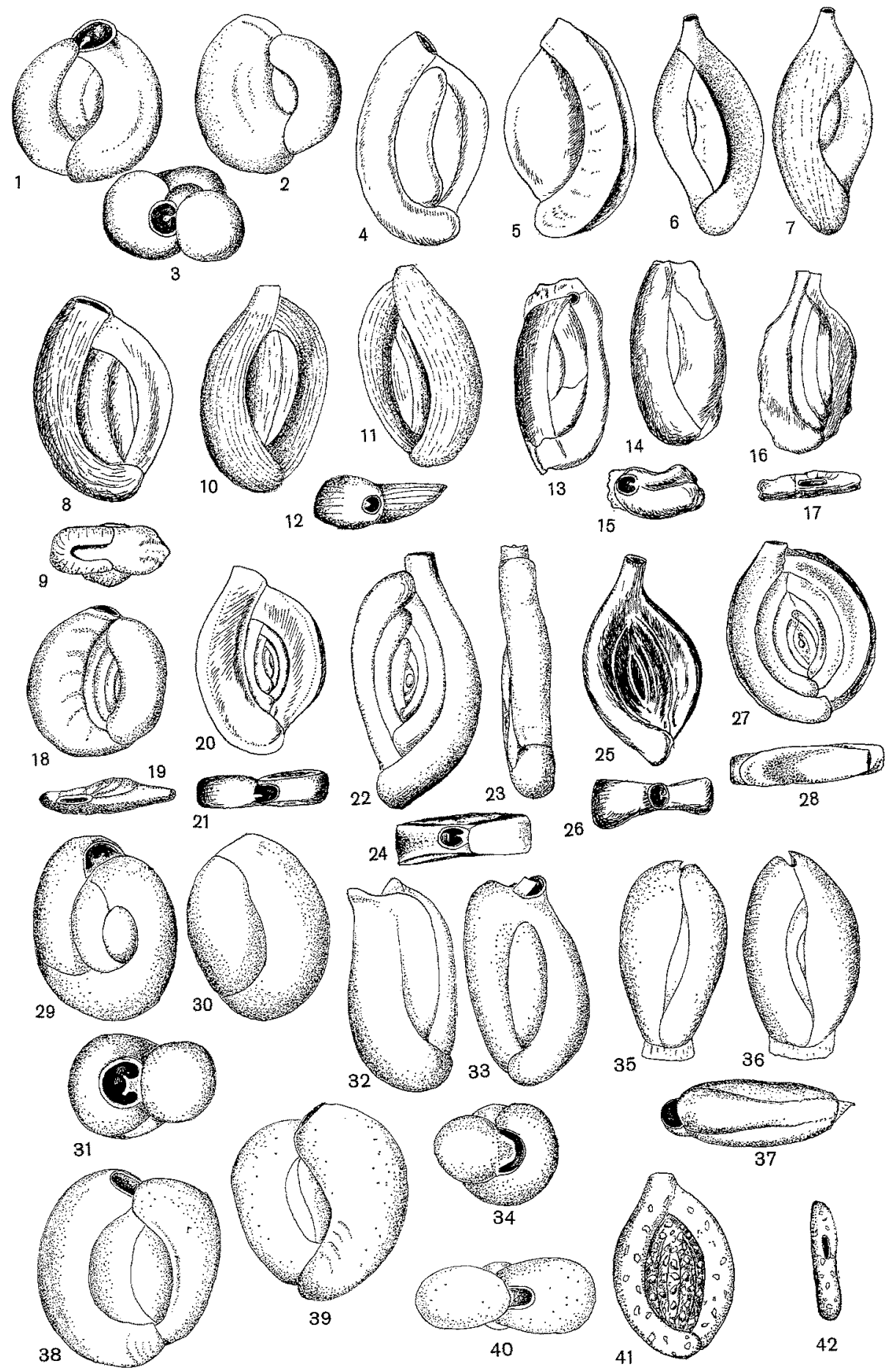

Tafel 6 


\section{Tafel 7}

1, 2 Triloculina tricarinata D'OrBignY $(50: 1)$

3,4 Triloculina trigonula (LAMARcK) $(40: 1)$

5,6 Triloculina trihedra Loeblich \& TappaN $(50: 1)$

7-9 Triloculina rotunda D'ORBIGNY $(20: 1)$

10, 11 Triloculina oblonga D'ORBIGNY $(40: 1)$

12,13 Miliolinella subrotunda (MontAgu) (50:1)

14, 15 Pyrgo oblonga (D'OrbignY) $(40: 1)$

16,17 Pyrgo depressa (D'OrbignY) (40:1)

18-20 Pyrgo subglobulus PARR (40:1)

21, 22 Pyrgo murrbyna (SCHWAGER) (50:1)

23,24 Pyrgo appendiculata (Reuss) (50:1): Norwegische Rinne

25, 26 Pyrgo lucernula (SCHWAGER) $(30: 1)$

27, 28 Prygo elongata (D'ORBIGNY) $(75: 1)$

29,30 Pyrgo laevis DerRance $(50: 1)$

31, 32 Pyrga comata (BRadr) (30:1)

33-35 Pyrgo sp. (50:1): vor Küste Ost-England

36, 37 Pyrgoella globula (BORNEMANN) $(50: 1)$

$38-40$ Biloculinella sp. $(40: 1)$

41, 42 Pyrgoella sphaera (D'ORBignX) $(50 ; 1)$ 
Foraminiferen der Nordsee
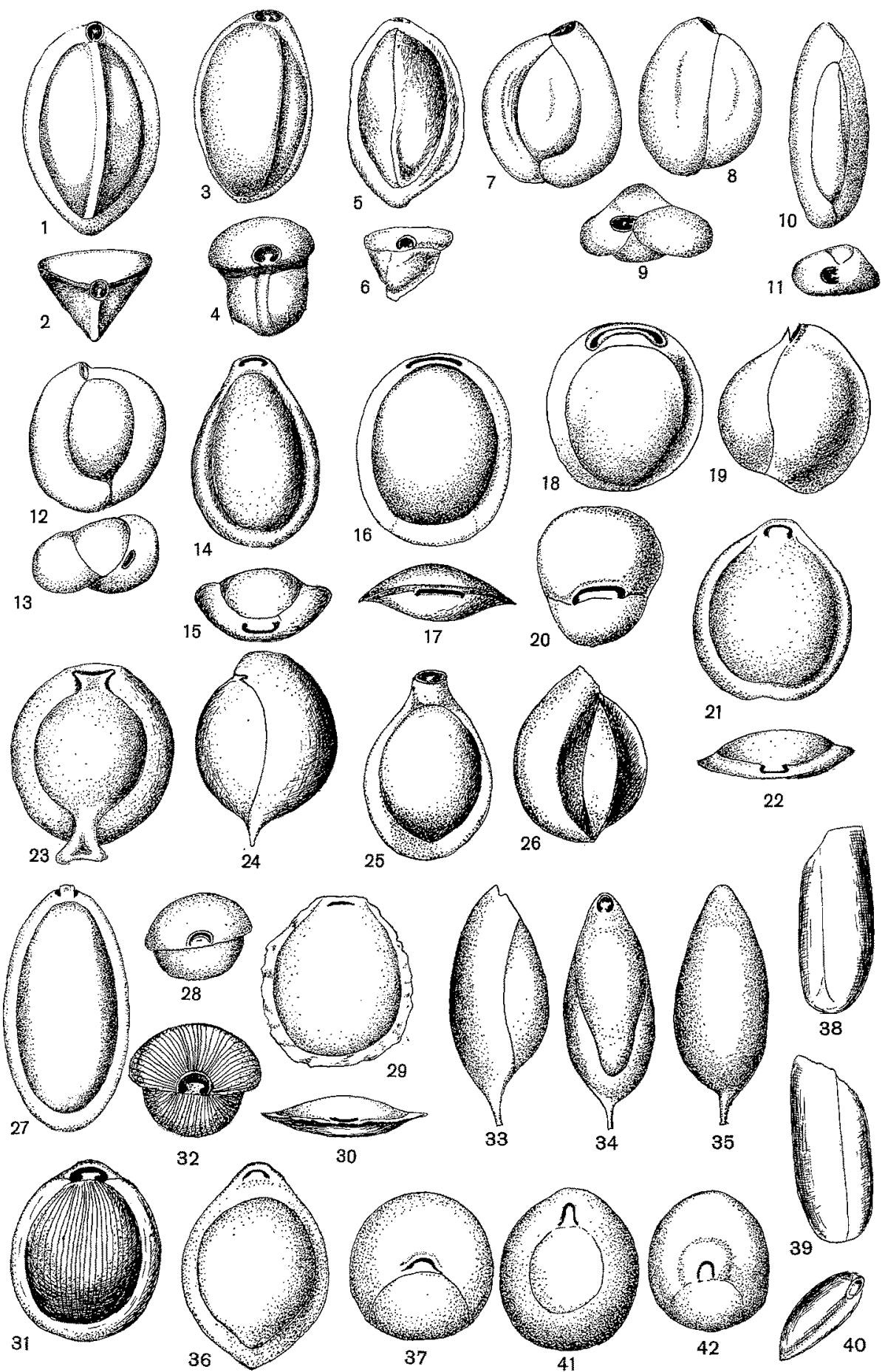

30
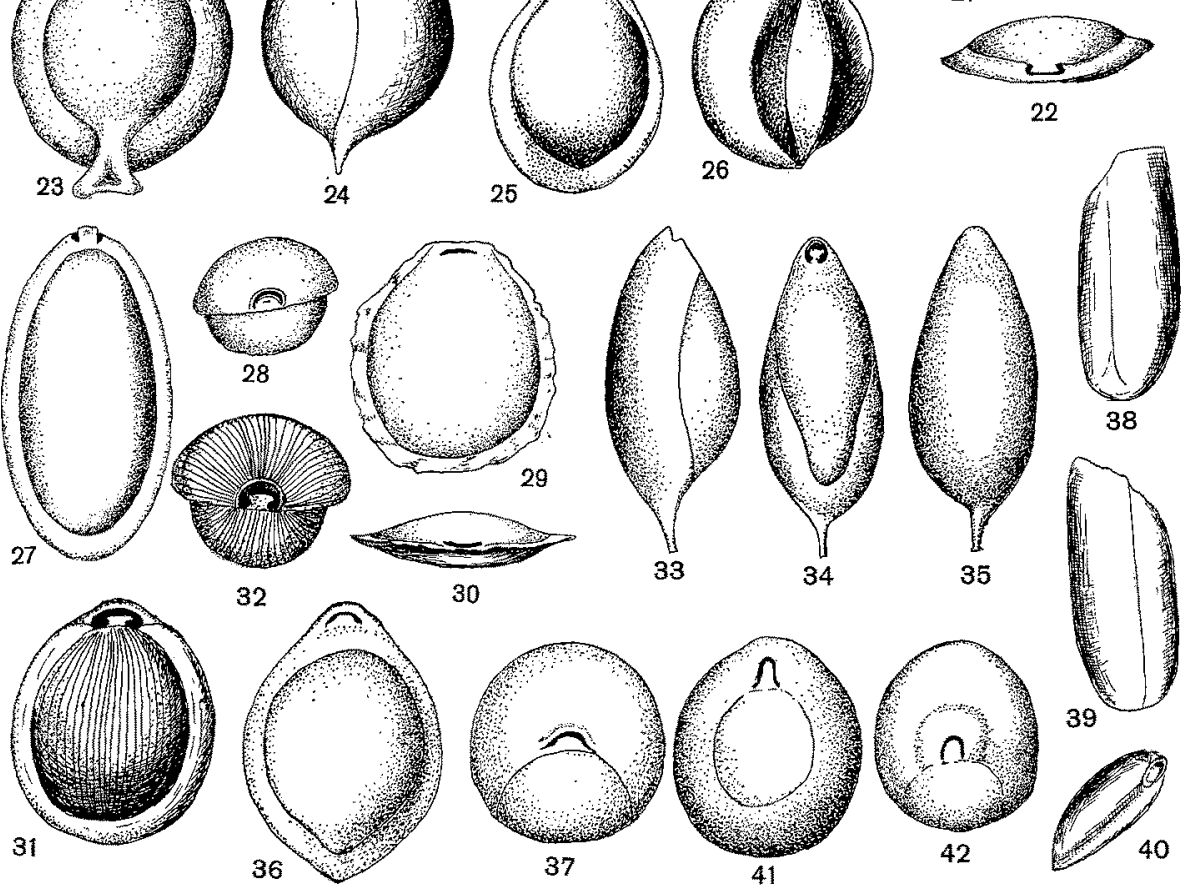

Tafel 7 


\section{Tafel 8}

1, 2 Cyclogyra involvens (Reuss) $(25: 1)$

3- 5 Trochammina labiosa Höglund (125:1)

6- 8 Trochammina ochracea (WILliamson) $(100: 1$ )

9-11 Trochammina adaperta. RHUMBLER $(80: 1)$

12-14 Trochammina nitida BRADY (80:1)

15-17 Trochammina stellata HöGLUND (80:1)

18-20 Remaneica belgolandica RHUMbler (115:1)

21-23 Trochammina squamata JONES \& PARKER (40:1)

24-26 Trochammina inflata (MONTAGU) $(40: 1)$

27-29 Trochammina nana (BRADY) $(100: 1)$

30-32 Trocbammina globigeriniformis (PARKER \& JONEs) (40:1)

33-35 Trochammina? sp. (40:1): aus dem Königshafen, Sylt

36-38 Trocbammina pusilla Höglund $(75: 1)$

39-41 Trochammina multioculata HöGLUND $(100: 1)$

42-44 Trochammina intermedia RHUMBLER $(100: 1)$

45-47 Trochammina astrifica RHUMBLER (100:1)

48-50 Jadammina polystoma BARTENSTEIN \& BRAND 1938 (40:1)

51 Jadammina polystoma: Mündungen 

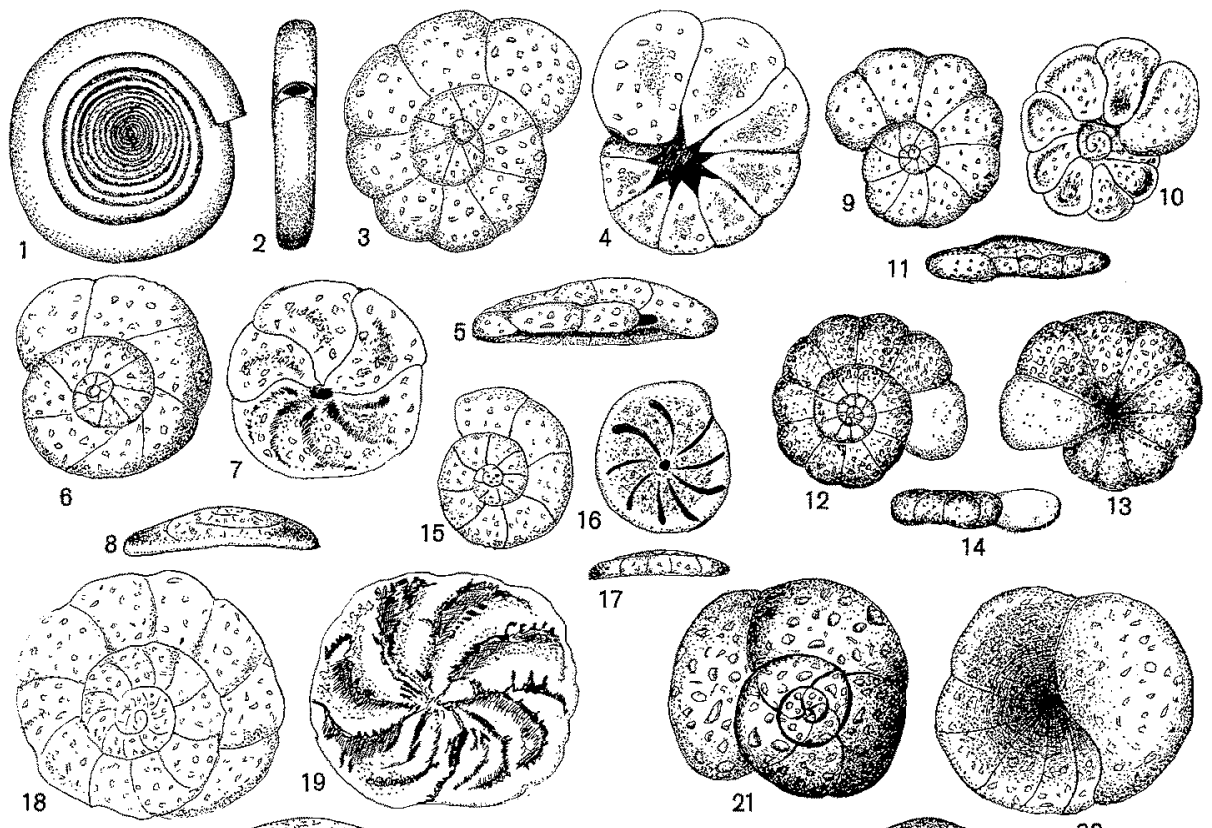

204 .
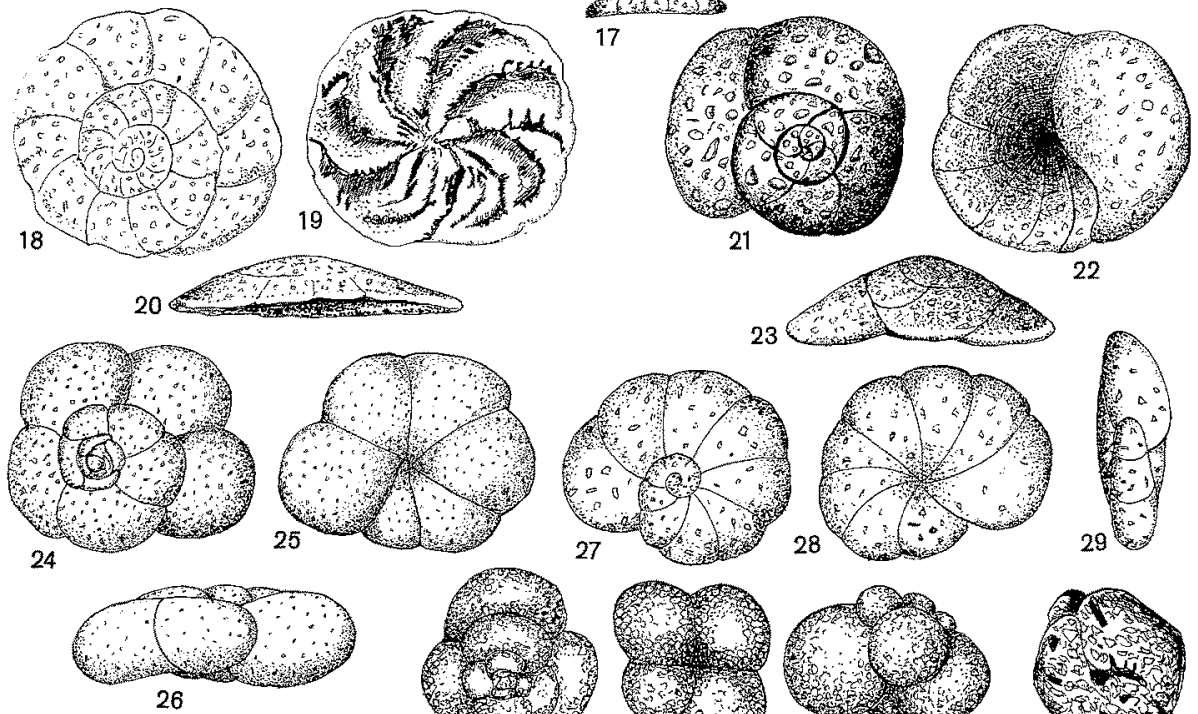

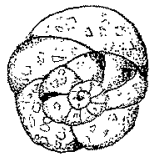

42

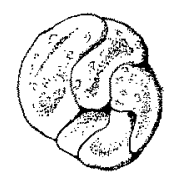

43
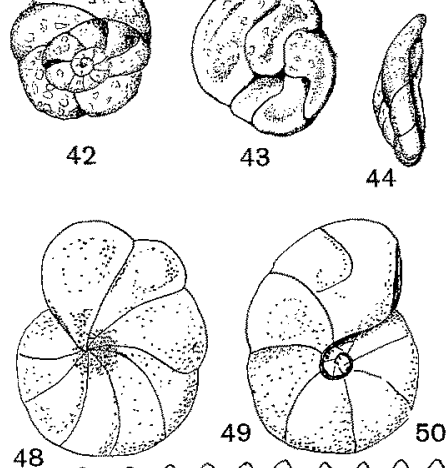

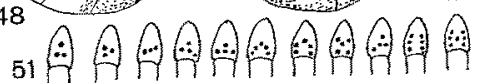
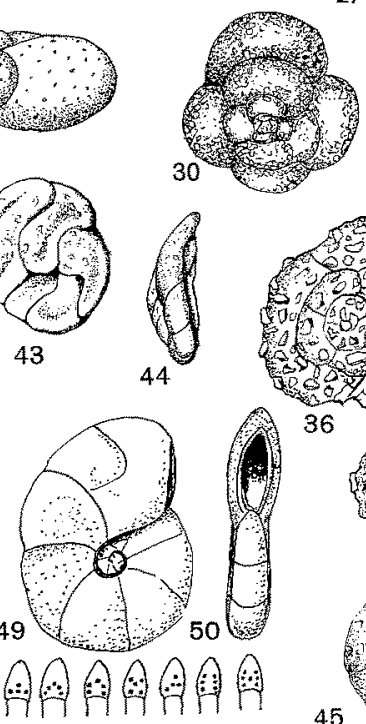

45
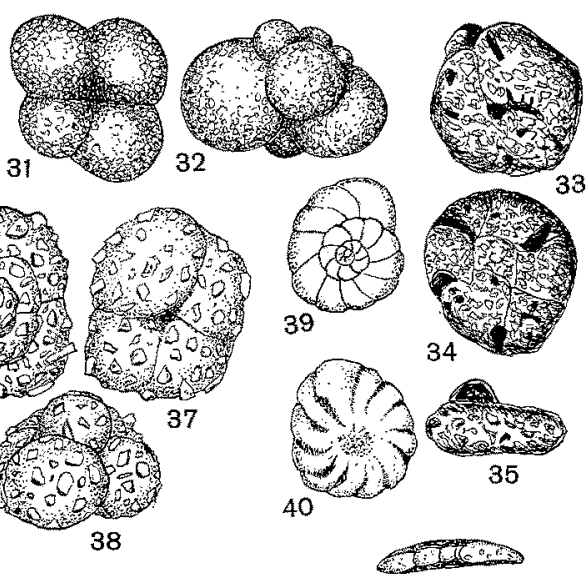

41
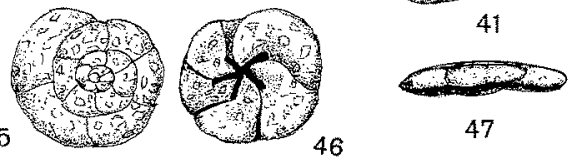

47

Tafel 8 


\section{Tafel 9}

1, 2 Lenticulina thalmanni (Hessland) $(30: 1)$

3,4 Lenticulina rotulata (LAMARCK) $(30: 1)$

5,6 Lenticulina rotulata $(25: 1)$

7,8 Lenticulina acutaturiculus (Fichtel \& MolL) $(75: 1)$

9 Lenticulina orbicularis (D'ORBIGNY) $(25: 1)$

10, 11 Lenticulina gibba (D'ORBIGNY) $(25: 1)$

12,13 Lenticulina convergens (BORNEMANN) $(40: 1)$

14-16 Lenticulina sp. (25:1): Deutsche Bucht

17, 18 Nodosaria lagenifera NeugEBoREN (30:1): glasklar

19 Nodosaria pyrula D'ORBIGNY $(30: 1)$ : weiß, porzellanartig

20 Nodosaria simplex Silvestru $(30: 1)$

21,22 Nodosaria calomorpha Reuss (30:1)

23 Nodosaria lamnulifera Boomgart $(15: 1)$

24 Amphicoryna separans (BRADY) (25:1) (früher: Nodosaria scalaris [BATsCH] var. separans)

25 Amphicoryna hirsuta (D'ORBIGNY) (20:1) (früher: Nodosaria)

26 Ampbicoryna sp. $(25: 1)$ : mittlere Nordsee

27, 28 Dentalina advena (Cushman) (20:1)

29, 30 Stilostomella consobrina (D'ORBIGNY) (30:1) (früher: Dentalina consobrina D'ORBIGNY)

31, 32 Dentalina subsoluta (CUshman) $(10: 1)$

33, 34 Dentalina inornata D'ORBIGNY var. bradyensis (Dervieux) $(40: 1)$

35, 36 Dentalina sp. (40:1): Deutsche Bucht

37,38 Oolina lagenoides (Willamson) $(50: 1)$

39 Lagena ornata (Williamson) $(75: 1)$

40,41 Fissurina quadrata (Williamson) $(50: 1)$

42,43 Fissurina danica MADson (50:1)

44,45 Oolina globosa (MonTAGU) $(75: 1)$

46, 47 Oolina trigono-oblonga Seguenza \& StDdall $(75: 1)$

48, 49 Lagena elongata (EHRENBERG) (50:1) 


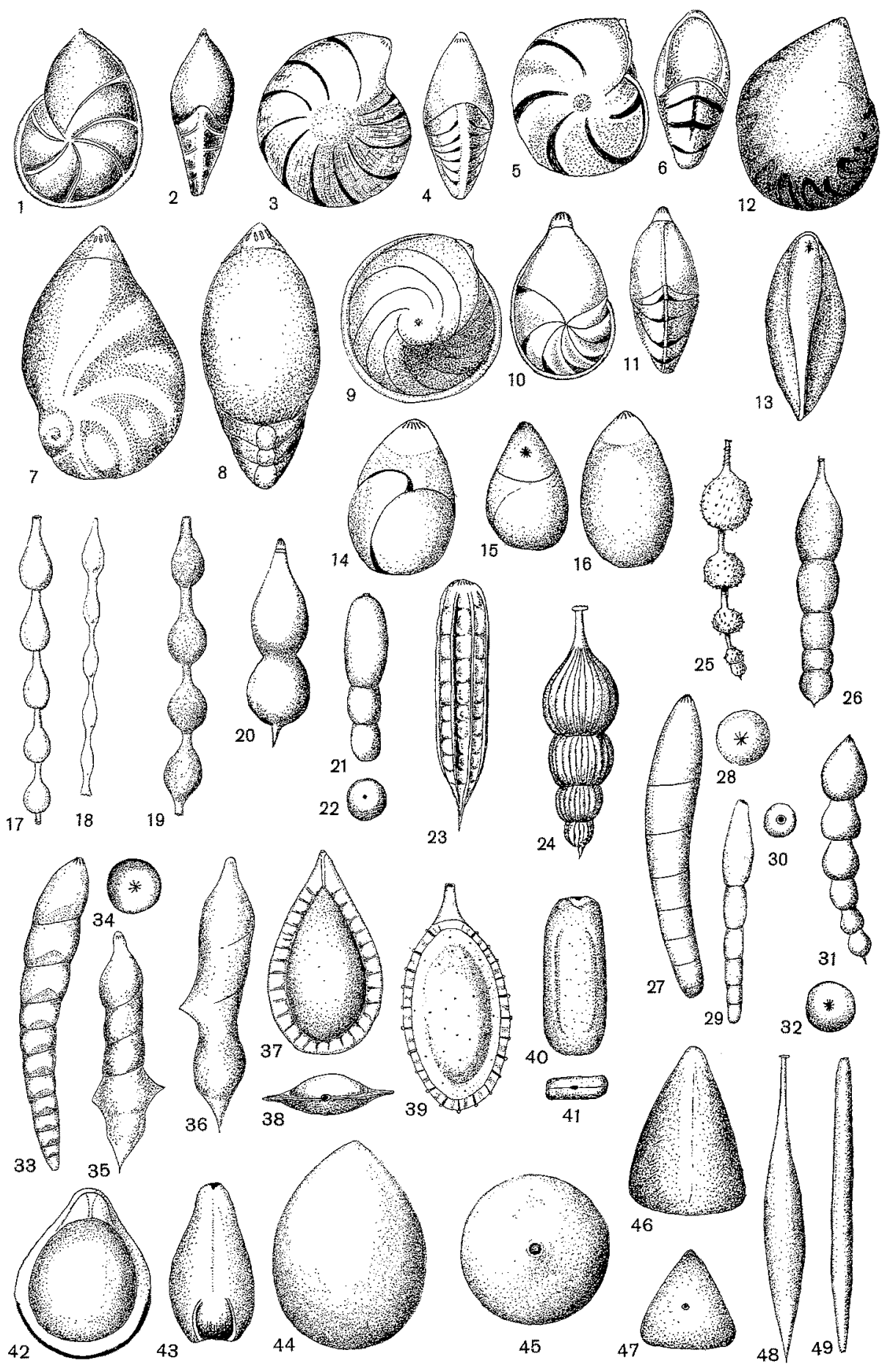

Tafel 9 


\section{Tafel 10}

1, 2 Lagena gracillima (SEGUENZA) $(60: 1)$

3 Lagena gracillima (Seguenza) var. (50:1)

4 Lagena distoma Parker, Jones \& Brady $(80: 1)$

5,6 Lagena distoma $(50: 1)$

7,8 Lagena gracilis Willtamson $(75: 1)=$ Amphorina costai ANDERSEN

9 Lagena clavata D'ORBIGNY $(75: 1)$

10 Lagena bispidula Cushman (75:1)

11, 16 Lagena substriata Wiltiamson 11 (100:1), 16 (150:1)

12 Lagena striata (D'ORRIGNY) $(100: 1)$

13 Lagena laevis (MonTAGU) $(125: 1)$

14 Lagena filicosta Reuss (75:1)

15 Lagena nebulosa Cushman $(60: 1)$

17 Lagena crenata PARKer \& JONES $(75: 1)$

18,19 Lagena perlucina WiLliamson $(75: 1)$

20 Lagena stelligera BRADY $(100: 1)$

21, 22 Lagena semistriata WiLliamson $(75: 1)$

23 Oolina bexagona (Williamson) $(100: 1)$

24 Oolina melo (D'OrbignY) $(90: 1)$

25 Oolina squamosa (MonTAGu) $(75: 1)$

26 Oolina elegantissima (BornemanN) $(60: 1)$

27 Oolina montagui Alcock $(75: 1)$ 
Foraminiferen der Nordsee
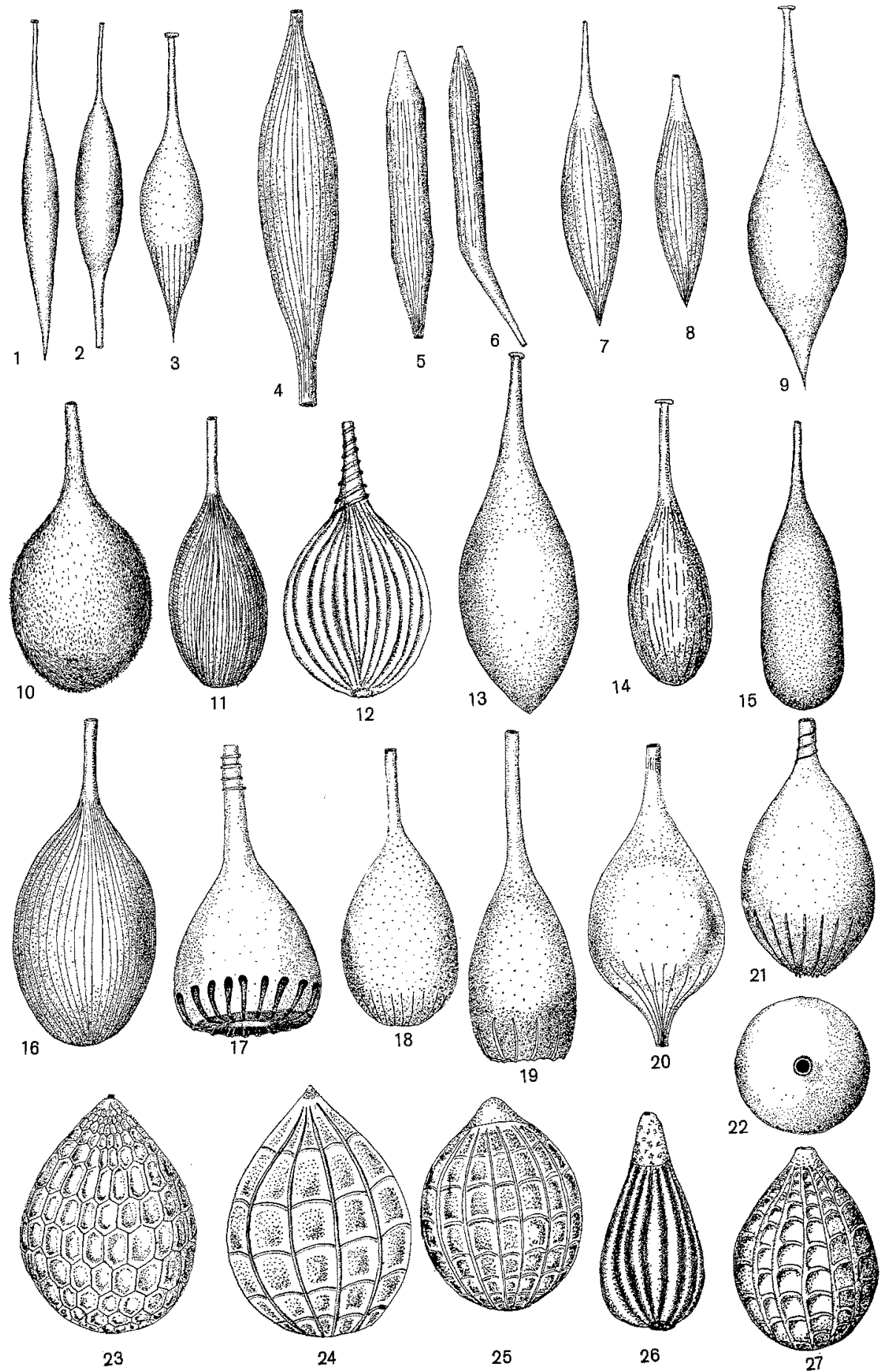

Tafel 10

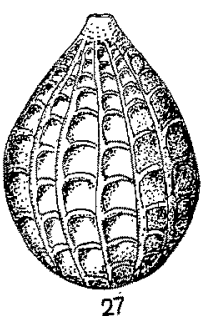




\section{Tafel 11}

1 Oolina acuticosta Reuss (150:1)

2 Oolina apiopleura LoEBLICH \& TAPPAN $(60: 1)$

3 Oolina sulcata (WALKER \& JACOB) $(90: 1)$

4 Oolina catenulata (Williamson) $(100 ; 1)$

5 Oolina costata (WILliamson) $(50: 1)$

6 Oolina williamsoni ALcock (50:1)

7,8 Pseudopolymorpbina ovalis (CusHMAN \& OZAWA) $(40: 1)$

9 Pseudopolymorphina novangliae Cushman (30:1)

10 Guttulina austriaca D'OrBTGNY (30:1)

11,12 Guttulina pacifica (Cushman \& Oza Wa) $(50: 1)$

13, 14 Polymorphina ovata D'ORBIGNY (30:1)

15-17 Polymorphina concava Williamson $(100: 1)$

18 Polymorphina myristiformis WILLIAMsON $(50: 1)$

19, 20 Sigmomorphina undulosa (TERQUEM) $(30: 1)$

21 Sigmomorphina semitecta Reuss var. terquemiana Cushman $(40: 1)$

22-24 Pyrulina fusiformis (ROEMER) (40:1)

25-27 Polymorpbina lactea (WALKER \& JACOB) $(50: 1)$

28, 29 Globulina minuta (ROEMER) (50:1)

30 Globulina glacialis Cushman \& Ozawa (40:1)

31, 32 Glabulina rotundata (Bor NEMANN) $(50: 1)$

33, 34 Globulina gibba D’ORBIGNY (50:1)

35, 36. Globulina inaequalis Reuss (80:1)

37-39 Polymorphina sp. cf. lactea WakKeR \& JACOB (50:1) 
Foraminiferen der Nordsee
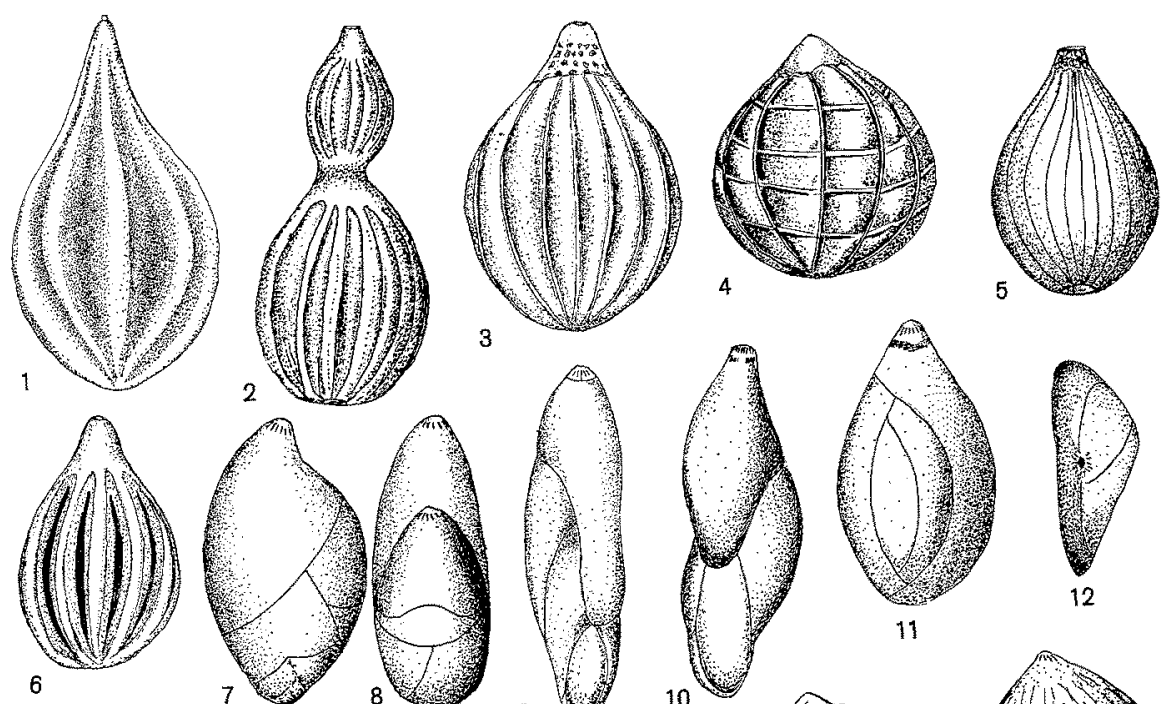

6
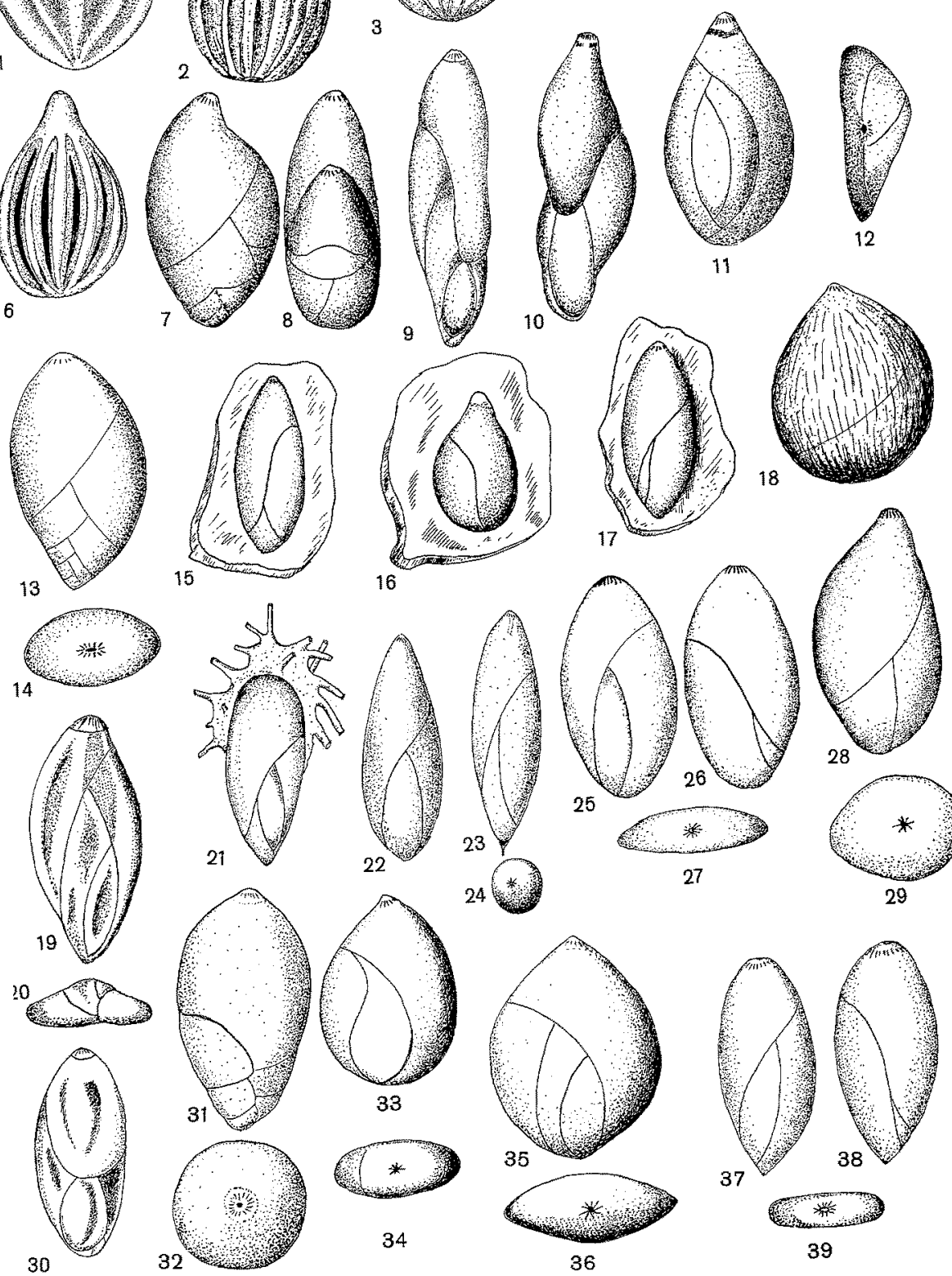

Tafel 11 


\section{Tafel 12}

1, 2 Pseudonodosaria rotundata (Reuss) (30:1)

3 Pseudonodosaria laevigata (D'ORBIGNY) $(30: 1)$

4, 5 Nodosaria sp. (30:1): mittlere Nordsee

6,7 Nonion depressulum (WALKER \& JACOB) (50:1)

8, 9 Melonis pompilioides (Fichtel \& MolL) $(75: 1)$

10, 11 Melonis umbilicatulum (MONTAGU) $(75: 1)$

12,13 Nonion ornatissimum CushMan (30:1)

14, 15 Nonion pauperatum BaLkwill \& WRIGHT $(75: 1)$

16, 17 Florilus cf. asterizans (Fichtel \& MOLL) $(75: 1)$

18, 19 Melonis barleeanum (WrLliamson) $(75: 1)$

20,21 Melonis zaandami (VAN VoORTHUYSEN) $(75: 1)$

22,23 Nonionellina labradorica (DAwson) $(40: 1)$

24, 25 Astrononion gallowayi Loeblich \& Tappan $(100: 1)$

26, 27 Nonionella turgida (Wrllamson) $(75: 1)$

28, 29 Nonionella scapha (FICHTEL \& MOLL) (75:1)

30-32 Nonionella atlantica Cusmman (40:1)

33-35 Nonionella warburgi BROTZEN (75:1)

36, 37 Nonionella sloani (D'OrBIGNY) $(50: 1)$ 


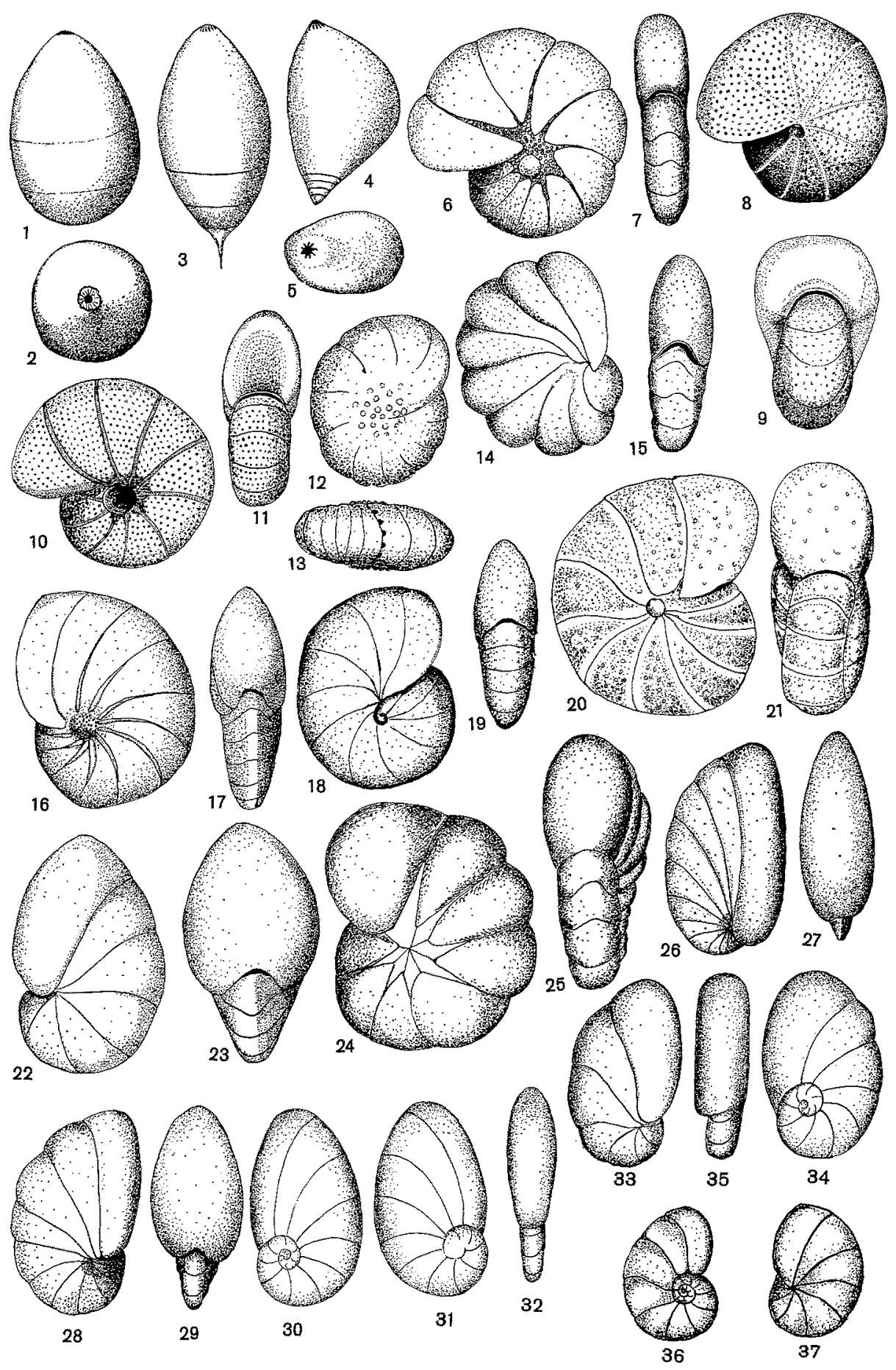

Tafel 12 


\section{Tafel 13}

1- 3 Nonionella auricula (Heron-mAlen \& Eart.ANd) $(40: 1)$

4- 6 Nonionella extensa (BrotzEN) (40:1)

7- 9 Cribrononion excavatum (TerqueM) $(50: 1)$

(= Elpbiditum selseyense Hiron-AlLEN \& EARLAND)

10, 11 Cribrononion excavatum (Terquem) $(50: 1)$

(= Elphidium clavatum Cushman)

12 Cribrononion excavatum clavatum (CUSHMaN) $(60: 1)$

(= Elphidium incertum clavatum CusHMAN)

13, 14 Cribrononion incertum (WILlamson) $(60: 1)$

15, 16 Cribrononion minutum (Reuss) (70:1)

17, 18 Cribrononion excavatum (TERquem) $(50: 1)$

19,20 Cribrononion incertum subsp. A. LuTzE $(60: 1)$

21, 22 Cribrononion alvarezianum (D'ORBIGNY) $(75: 1)$

23, 24 Cribrononion gunteri (COLE) $(60: 1)$

27, 28 Cribrononion asklundi (BROTZEN) (50:1): Brackwasserform

25, 26 Elphidium aculeatum (D'ORBIGNY) $(50: 1)$ : sehr selten

29,30 Elphiditum lessonii (o'OrBIGNY) $(50: 1)$

31,32 Elphidium macellum (Fichtel \& MolL) (50:1)

33,34 Elpbidium crispum (LINNE) $(50: 1)$

35, 36 Elphidium advenum CusHMAN $(50: 1)$ : Watt, südliche Nordsee

37,38 Cribrononion excavatum (TERquEM) (50:1): Watt, südliche Nordsee (= Elphidium margaritaceum CUSHMAN)

39, 40 Cribrononion voorthuyseni (HAAKE) (50:1): Watt, südliche Nordsee

41 Cribrononion gertbi (Voor THuYsen) (50:1): Watt, sïdliche Nordsee 

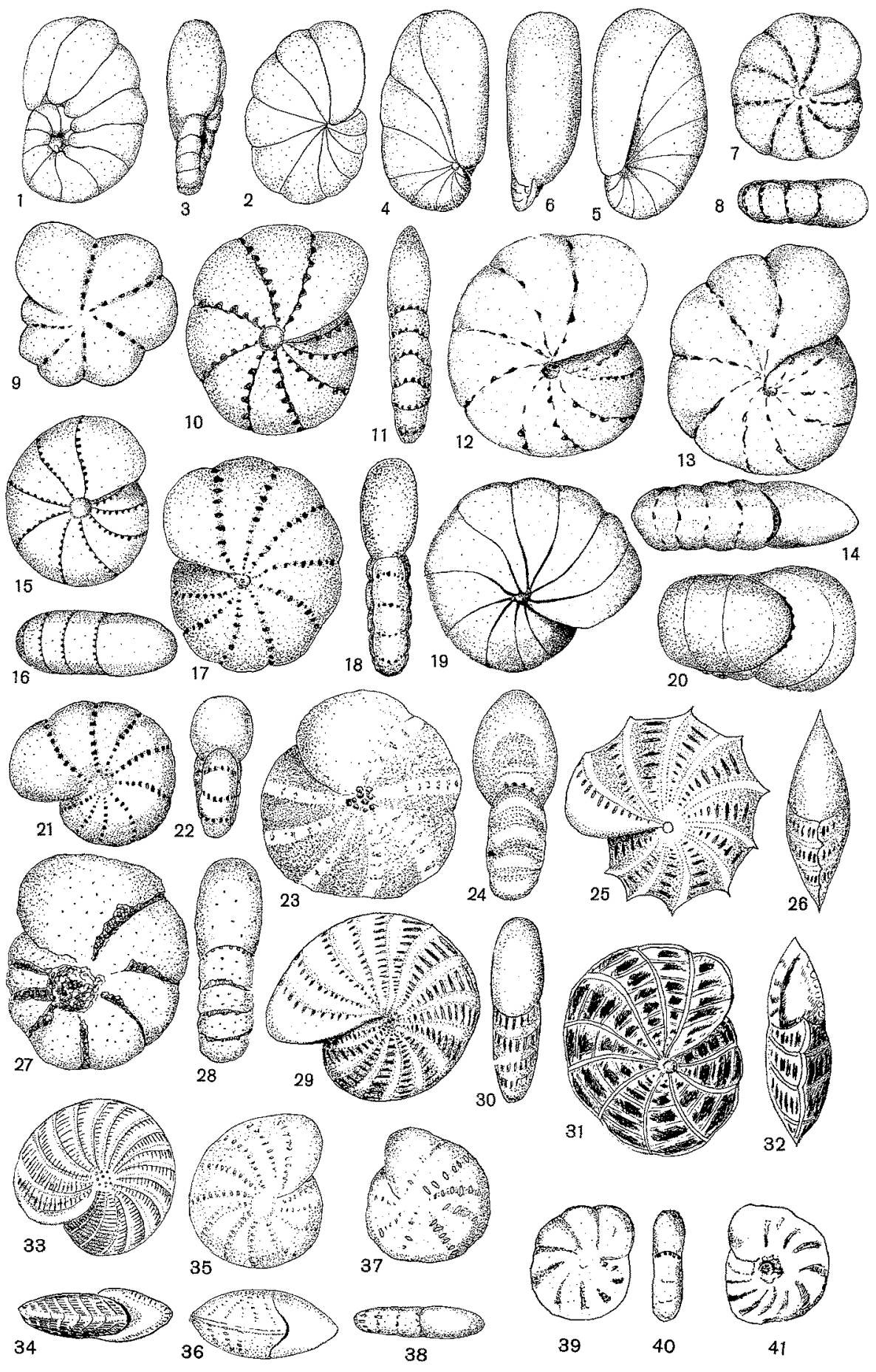

Tafel 13
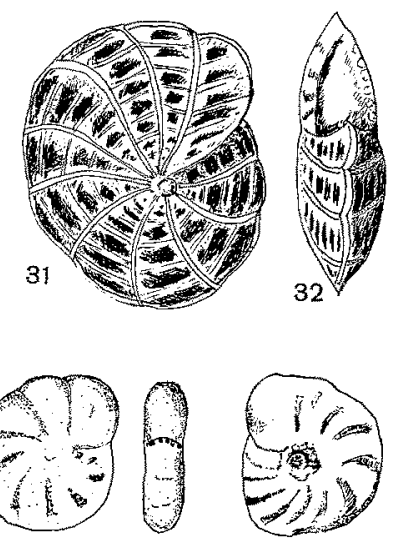

41 


\section{Tafel 14}

1- 3 Buliminella elegantissima (D'ORBIGNY) $(100: 1)$

4 Robertina arctica D'OrBIGNY $(70: 1)$

5- 7 Robertinoides pumilum HögLund $(70: 1)$

8 Robertinoides suecicum Höglund $(70: 1)$

9 Robertinoides normani (GoEs) $(70: 1)$

10,11 Bulimina aculeata D'OrbignY $(50: 1)$

12 Bulimina marginata D'ORBIGNY (50:1)

13 Bulimina submarginata PARR (50:1): nördliche Nordsee

14-16 Bulimina fusiformis Williamson $(40: 1)$ : gesamte Nordsee

17 Bulimina gibba ForNasinI $(60: 1)$

18 Praeglobobulimina pupoides (D'ORBIGNY) (50:1)

19, 20 Praeglobobulimina elongata (D'ORBIGNY) (50:1)

21 Globobulimina turgida (BAILEY) $(30: 1)$

22 Globobulimina auriculata (BAILEY) $(30: 1)$

23 Stainforthia concava (Höglund) $(90: 1)$

24 Stainforthia skagerakensis (HöGLUND) $(50: 1)$

25, 26 Stainforthia subdepressa (BRADY) $(25: 1)$

27,28 Brizalina gramen (D'ORBIGNY) $(100: 1)$

29,30 Brizalina alata (SEgueNzA) $(50: 1)$

31 Brizalina pseudopunctata (HögluND) $(100: 1)$

32,33 Brizalina earlandi (PARR) $(50: 1)$

34,35 Brizalina robusta (BRADY) $(50: 1)$

36,37 Sigmavirgulina tortuosa (BRADY) $(75: 1)$

38,39 Bolivina? pseudoplicata Heron-Allen \& EARLAND (100:1)

40, 41 Brizalina spatbulata (Williamson) $(100: 1)$

42,43 Bolivina? porrecta BRADY (50:1)

44 Brizalina striatula (CushmaN) $(75: 1)$ 
Foraminiferen der Nordsee

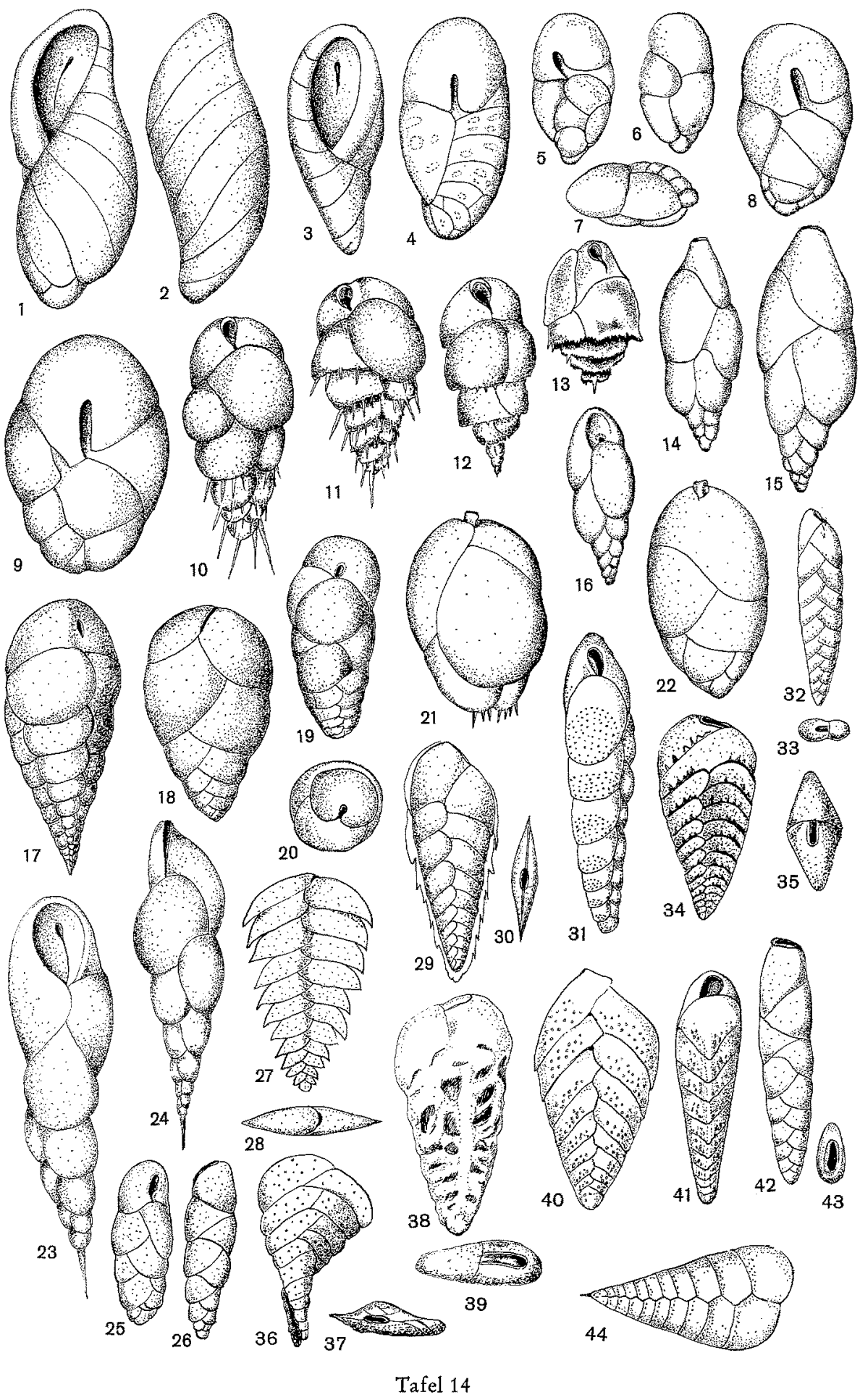




\section{Tafel 15}

1, 2 Brizalina variabilis (WILLAMSON) $(75: 1)$

3 Brizalina difformis (WILLAMSON) $(75: 1)$

4, 5 Brizalina subspinescens (CushmaN) (60:1)

6, 7 Brizalina psendopunctata (Höglund) (90:1)

8, 9 Eunvigerina peregrina (CushmaN) $(30: 1)$

10, 11 Uvigerina cf, striata D'OREIGNY (40:1)

12,13 Rectobolivina bifrons (BRADY) (50:1)

14 Rectobolivina dimorpha (PARKer \& Jones) (75:1)

15,16 Trifarina angulosa (Williamson) $(40: 1)$

17, 18 Trifarina fluens (TODD) $(60: 1)$

19,20 Trifarina bradyi Cushman $(75: 1)$

21, 22 Spirillina vivipara EhRENBERG $(30: 1)$

23-25 Planispirillina wrightii (HERON-AlLEN \& EARLAND) (40:1)

26-28 Spirillina lucida SidebotTom (60:1)

29-31 Patellina corrugata WrLlamson $(60: 1)$

32,33 Fissurina laevigata (Reuss) (50:1)

34, 35 Fisstrina lucida (WILLIAMSON) $(60: 1)$

36,37 Fissurina marginata (MonTAGU) $(50: 1)$

38,39 Fissurina cucurbitasema LOEBLIch \& TAPPAN (100:1)

40, 41 Fissurina orbignyana (SEGUENZA) (100:1)

42,43 Parafissurina lateralis (CushmAN) $(100: 1)$

44 Parafissurina elliptica (SEgUENZA) (40:1)

45, 46 Trifarina pygmaea nov. sp. (100:1)

Beschreibung: Gehäuse triangular, Suturen verwischt, Kammern leicht aufgebläht, sehr schwache und wenige Längsstreifen, perforierte Wandung. Kurze Halsröhre und ausgeprägter Mündungsrand. Form oval. Drei stark ausgeprägte Leisten an den 3 Kanten. Mündung mit kleinem Zahn und Zahnplatte. Länge (max.): $0,28 \mathrm{~mm}$, Breite (max.) $: 0,16 \mathrm{~mm}$. $T$. pygmaea ähnelt $T$. angulosa, ist aber wesentlich kleiner und hat nicht die ausgeprägten Längsrippen. Die Mündung von $T$. pygmaea ist gebördelt, im Gegensatz zu T. angulosa. Im Querschnitt ist T. pygmaea wesentlich stärker angular als $T$. angulosa. T. pygmaea tritt in der südlichen Nordsee (vor den Ostfriesischen Inseln) auf. Holotyp: DHI, M411/1. 
Foraminiferen der Nordsee

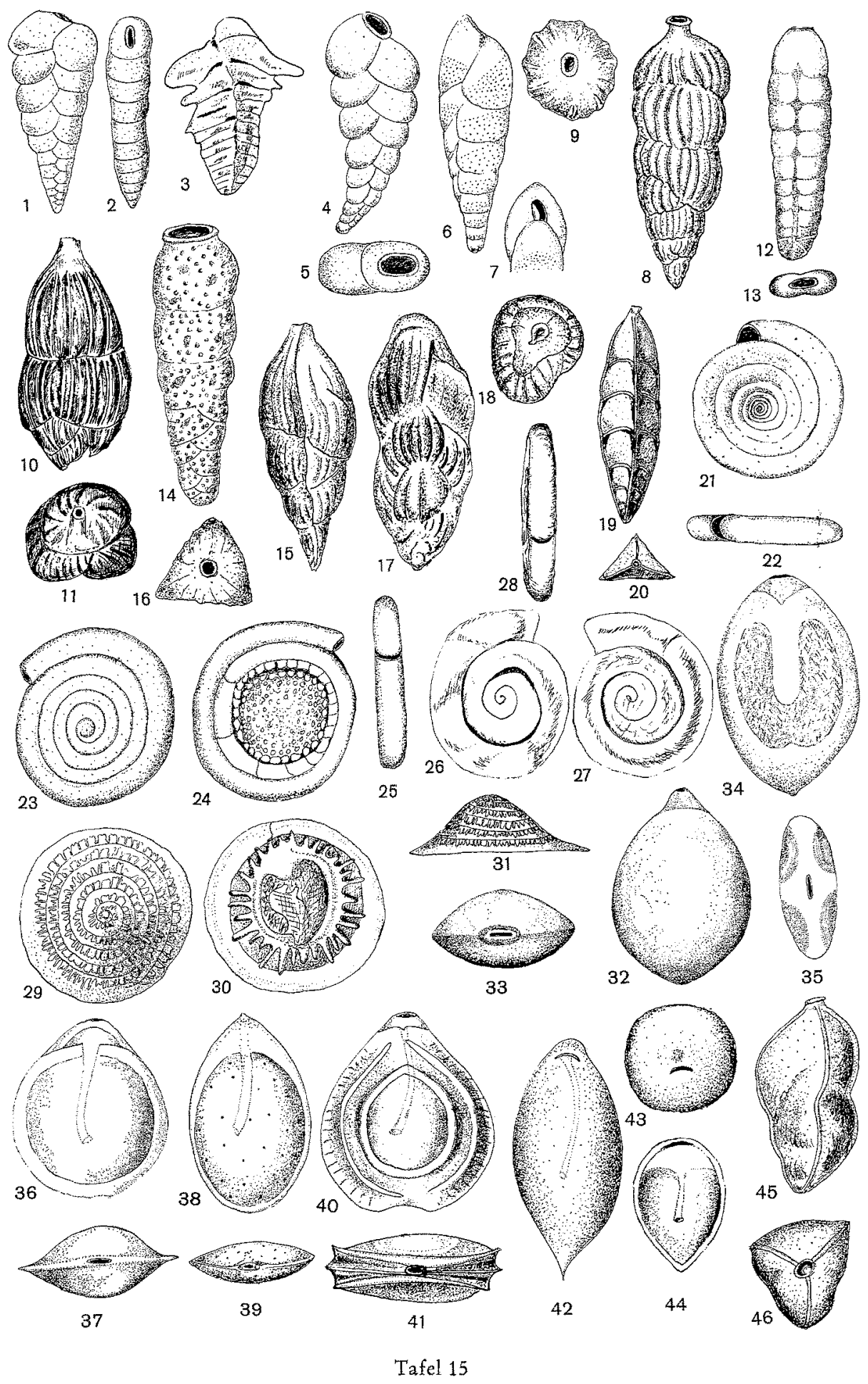




\section{Tafel 16}

1- 3 Rosalina vilardeboana D'ORBIGNY $(75: 1)$

4- 6 Discorbis rosacea (D'ORBIGNY) $(30: 1)$

7,8 Discorbinella bertbeloti (D'ORBTGNY) $(50: 1)$

9-11 Rosalina bradyi (Cushman) (50:1) (Discorbis globularis bradyi [Cushman])

12-14 Neoconorbina terquemi (RZEHAK) (50:1) (= Rosalina orbicularis [TERQuEM]) (vgl. Challenger Report, Taf 88, Fig. 4-8)

15-17 Discorbis nitida (Wrlliamson) $(50: 1)$

18-20 Rosalina concinna (BRADY) (100:1)

21-23 Discorbis floridiana CusHMan $(60: 1)$

24-26 Eponides repandus (Ficrtel \& MoLL) $(40: 1)$

27-29 Eponides frigidus CUSHMAN $(75: 1)$

30-32 Epistominella exigua (Brady) $(60: 1)$

33-35 Gyroidinoides soldanit (D'ORBIGNY) $(40: 1)$

36-38 Rosalina sp. (50:1): auf Deutsche Bucht beschränkt 

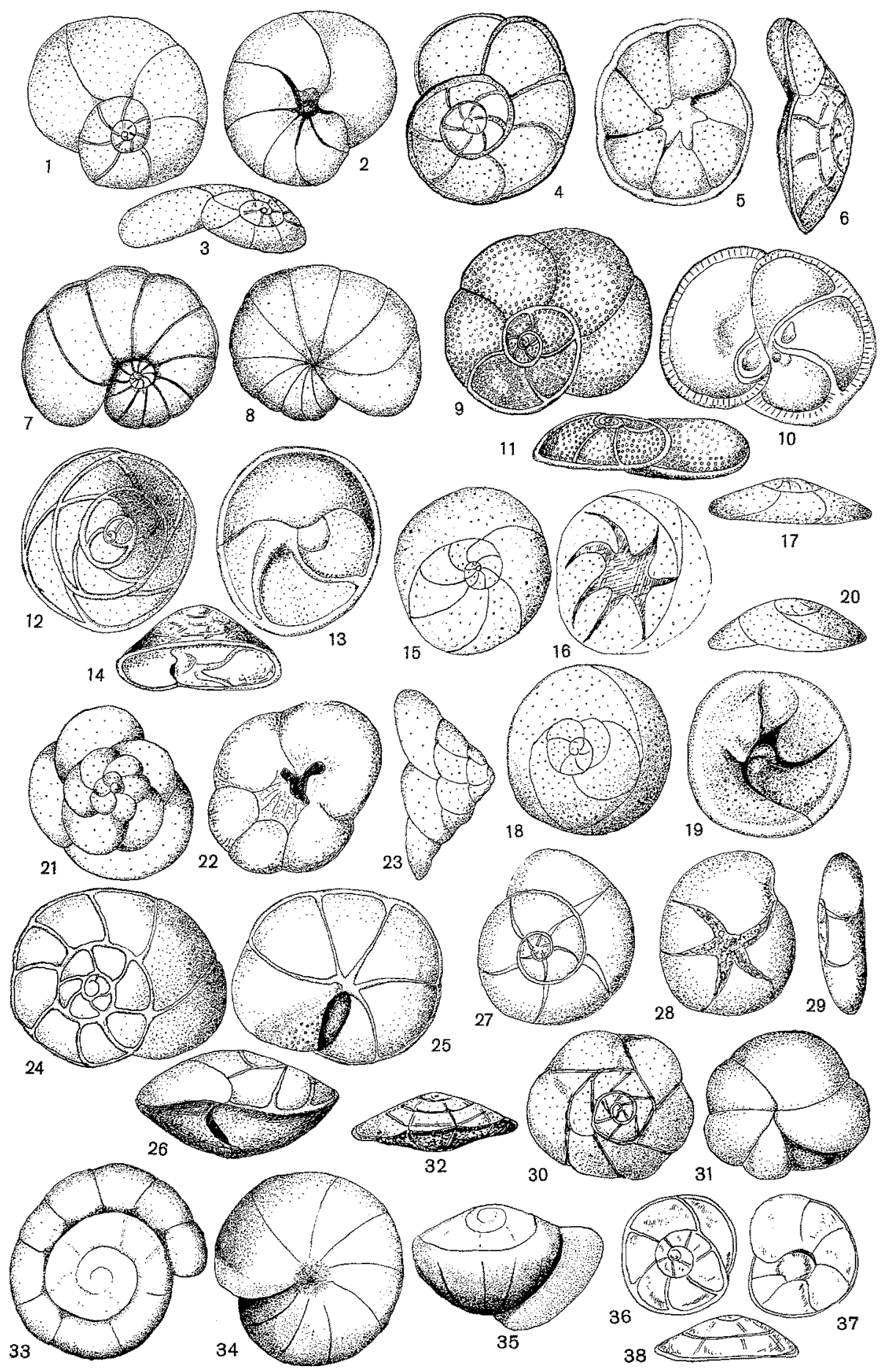

32
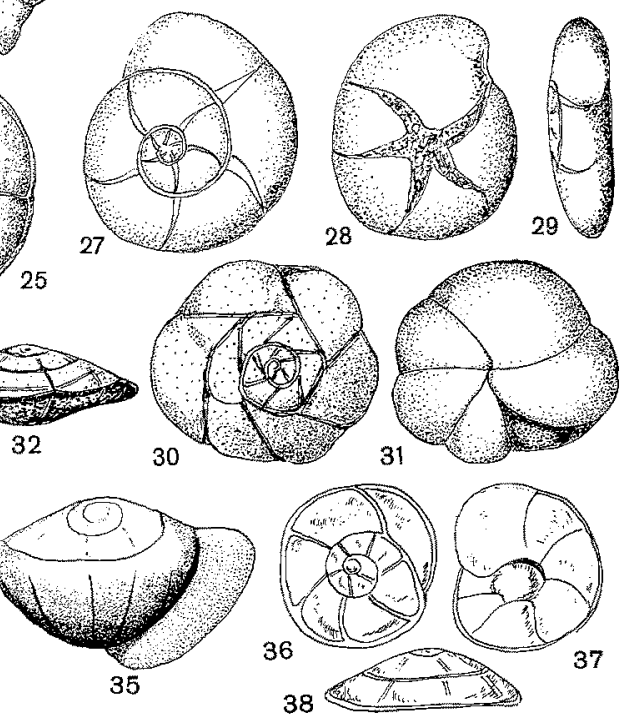

Tafel 16 


\section{Tafel 17}

1- 3 Ammonia beccarii (LinNé) (50:1)

4- 6 Gyroidina orbicularis D'ORBIGNY $(60: 1)$

7-9 Cassidulina laevigata D'ORBIGNY (50:1)

10-12 Globocassidulina crassa (D'ORBIGNY) $(60: 1)$

27, 28 Globocassidulina crassa (40:1)

13,14 Islandiella islandica (NøRVANG) $(75: 1)$

15-17 Globocassidulina nitida (CHASTER) (60:1)

18,19 Cassidulina norcrossi Cushman (50:1)

20-22 Cassidulina sp. aff. C. pulchella D'OrBignY (50:1)

23, 24 Globocassidulina subglobosa (BRADY) $(40: 1)$

25, 26 Cassidulina teretris TAPpan (40:1)

29,30 Islandiella ngrvangi THALMANN $(75: 1)$

31 Cassidulina carinata SILvestri $(75: 1)$

32 Cassidulina curvata Phleger \& Parker (50:1)

33,34 Cassidulinoides bradyi NoRMan $(75: 1)$

35, 36 Chilostomella ovoidea Reuss (50:1)

37,38 Pullenia subcarinata (D'ORBIGNY) $(30: 1)$

39,40 Pullenia bulloides (D'ORBIGNY) (50:1) 

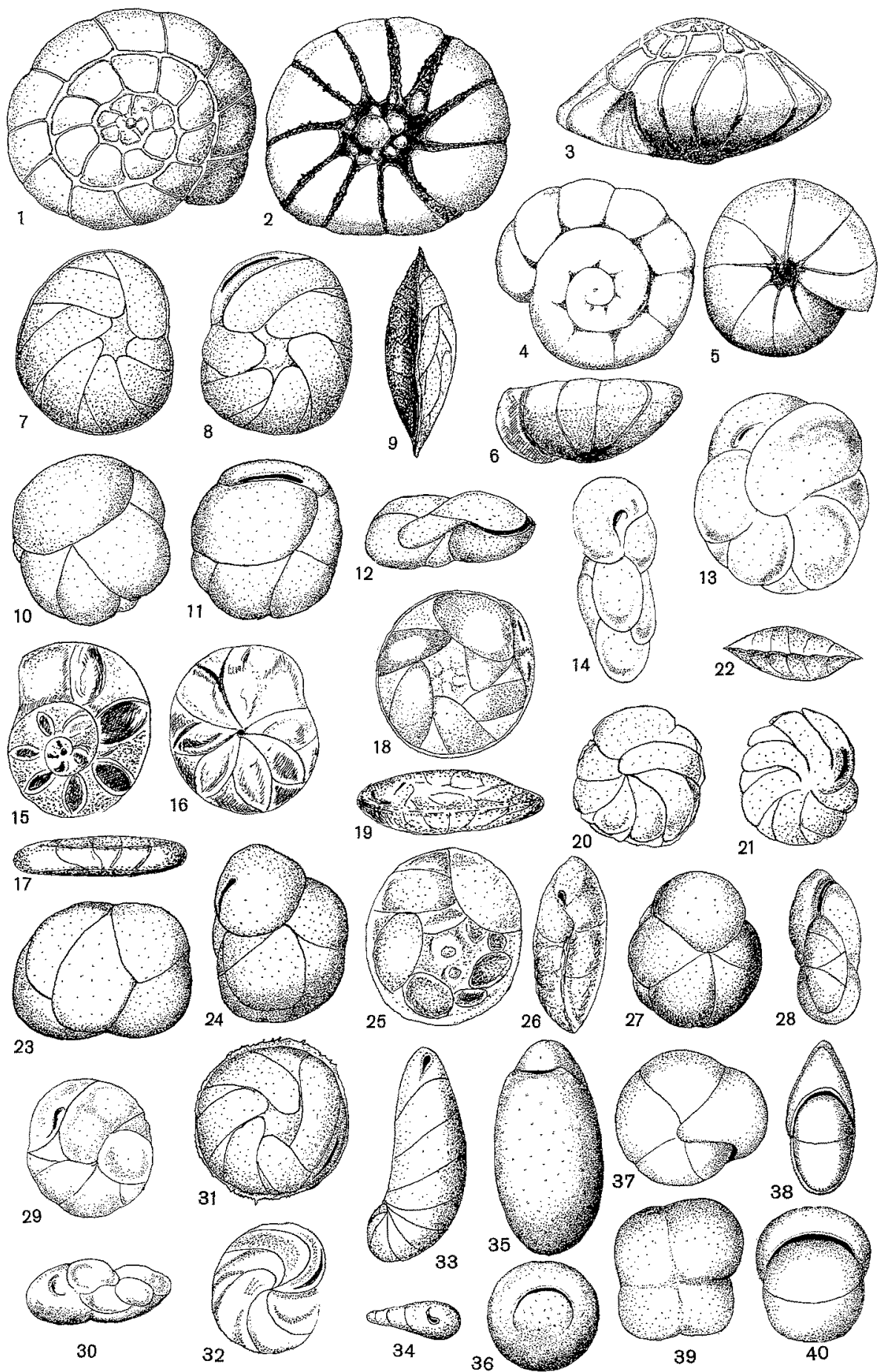

Tafel 17 


\section{Tafel 18}

1, 2 Sphaeroidina bulloides D'ORBIGNX $(30: 1)$

3, 4 Globigerina bulloides D'ORBIGNY $(75: 1)$

5- 7 Glabigerina dutertrei D'ORBIGNY $(80: 1)$

8-10 Globigerina pacbyderma (EHRENBERG) (80:1)

11,12 Utbergangsformen von Globigerina dutertrei zu Globigerina pacbyderma $(50: 1)$

13-15 Globigerinoides triloba (Reuss) $(60: 1)$

16-18 Globigerina eggeri RhumbieR (50:1)

19, 20 Globigerina sp. (50:1) (vgl. H. B. Brady 1884, Taf. 81, Fig. 6, 7)

21 Orbulina universa D'ORBrGNY $(40: 1)$

22, 23 Hyalinea baltbica (SCHroeter) $(60: 1)$

24-29 Hyalinea aberrante Formen (Mutationen?)

30,31 Paromalina coronata (PARKer \& Jones) $(30: 1)$

32-34 Cibicides lobatulits (WALKER \& JACOB) $(60: 1)$

35,36 Cibicides sp. aff. C. refulgens Montrort (80:1) 
Foraminiferen der Nordsee
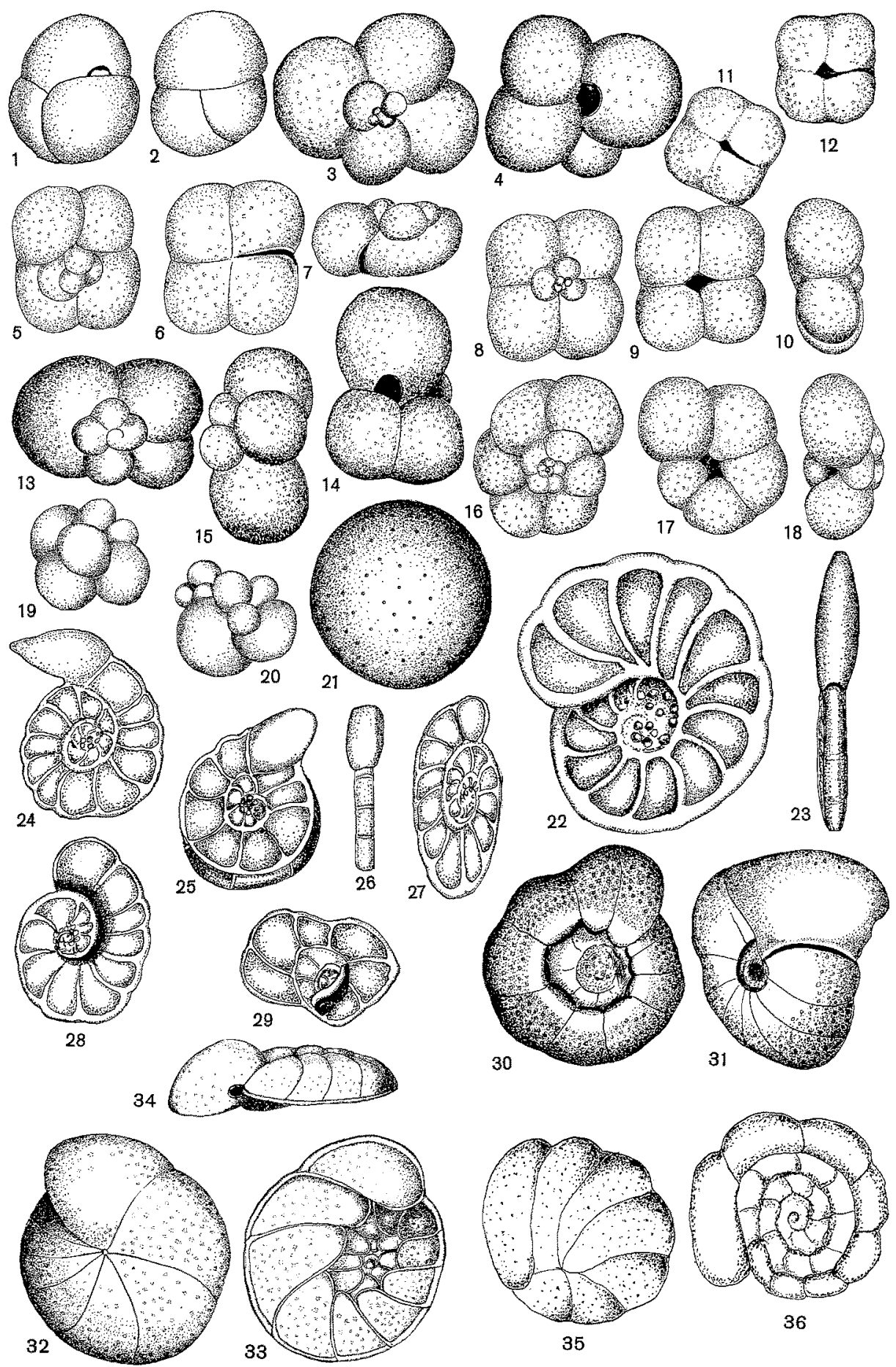

Tafel 18 


\section{Tafel 19}

1- 3 Cibicides pseudoungerianus (CUSHMAN) $(25: 1)$

4- 6 Cibicides refulgens Montrort (30:1)

7- 9 Planulina wuellerstorfi (SCHWAGER) $(30: 1)$

10-12 Cibicides perlucina NutTal $(40: 1)$

13,14 Dyocibicides uniserialis Thalmann $(50: 1)$

15 Dyocibicides biserialis Cushman \& Valentrine $(50: 1)$

16,17 Cibicidella vatriabilis (D'ORBIGNY) $(40: 1)$

18-20 Planorbulina mediterranensis D'ORBIGNY $(30: 1)$

21-23 Acervulina inhaerens SCHULTZE $(30: 1)$

24, 25 Gypsina vesicularis (PARKER \& JONEs) $(30: 1)$

26 Hippocrepina pusilla (HERON-AlLEN \& EARLAND) $(75: 1)$

27 Hippocrepina acuta Höglund $(75: 1)$

28-30 Halypbysema tumanowiczii Bowerbank $(25: 1)$

31, 32 Saccodendron heronalleni RHUMBLER forma latericum RHUMBLER (25:1): auf Bryozoen aufgewachsen 

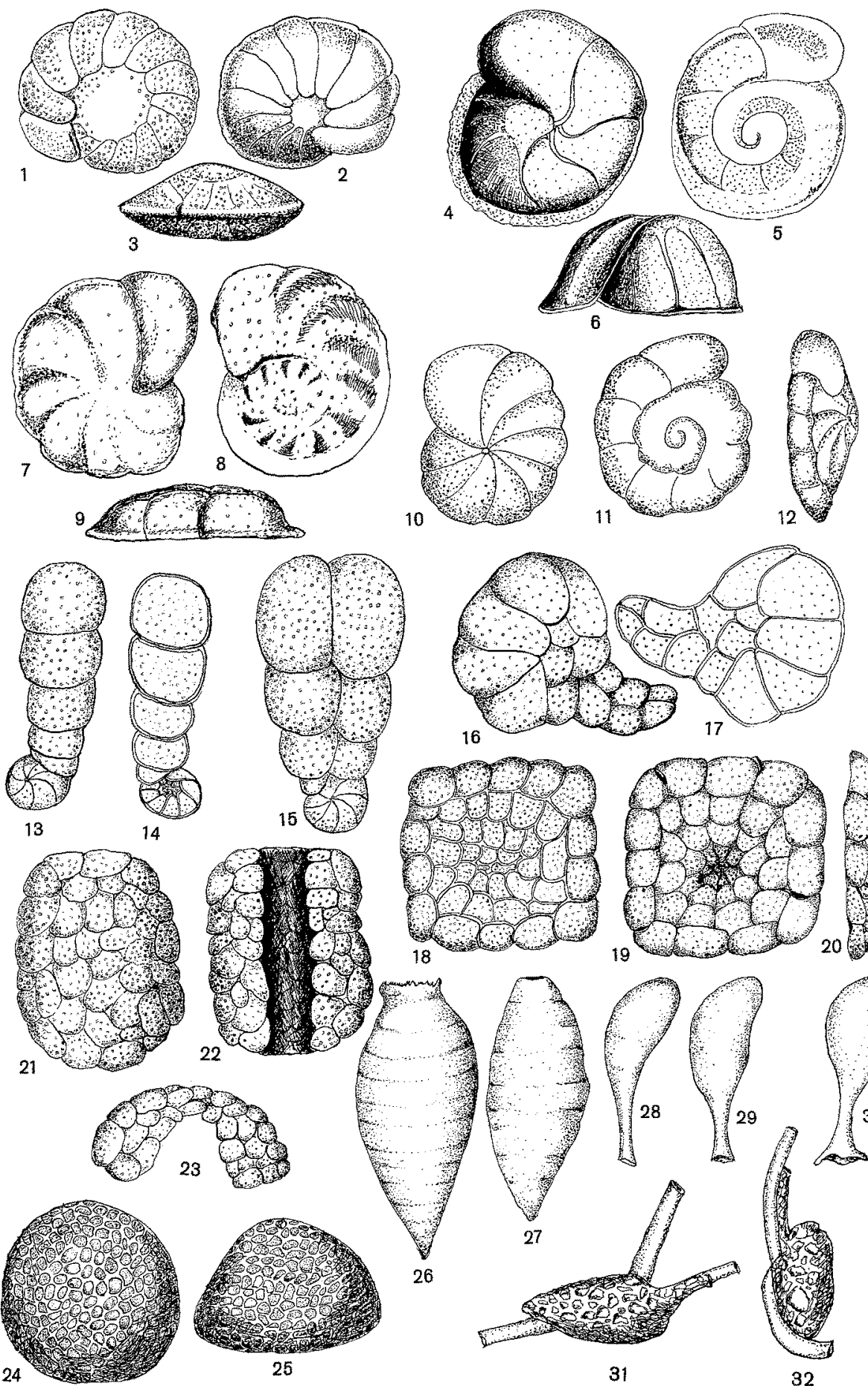

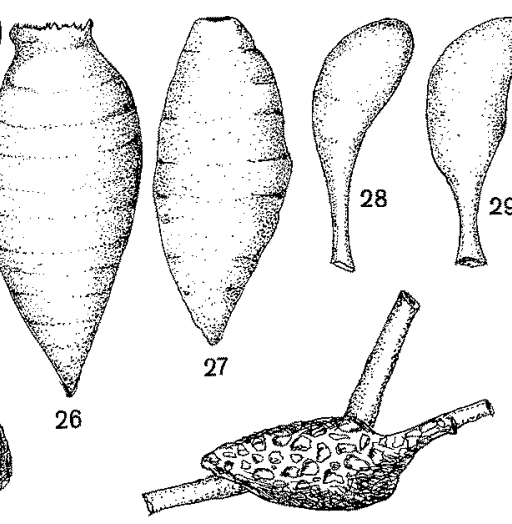

31

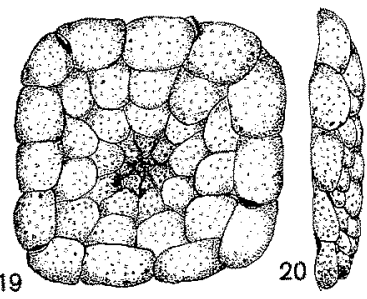

Tafel 19 
Tafel 20

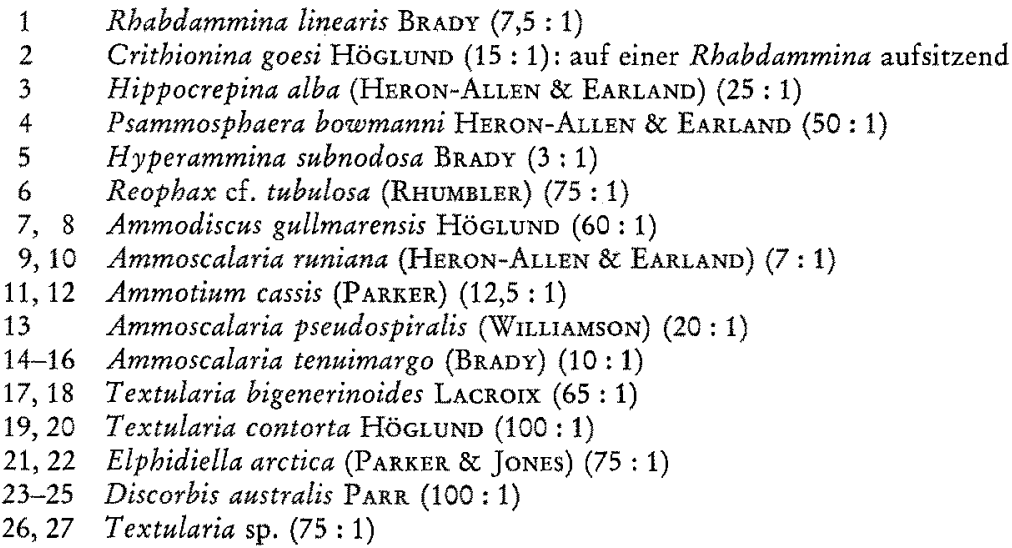

\section{Mündungsformen}

a Freies Ende der Spiralröhre

b Basale, ovale Mündung

c Sichelförmige subterminale Mündung

d, e Endständige schlitzförmige Mündung, mit einer inneren („entosolenian“) Röhre verbunden

f Tränenförmige Mündung mit innerer Zahnplatte (bulimin)

g Gerundete Mündung mit einem gespaltenen oder gegabelten Zahn

h Gerundete Mündung mit einem sägeförmigen Zahn

i V-förmige Mündung

j Flaschenförmige Mündung mit gebördeltem Rand

$\mathrm{k} \quad$ Einfache Mündung, beiderseits

1 Sternförmige oder strahlige Mündung

m Schlitzförmige Mündung an der Basalnaht der letzten Kammer

n Dendritische Mündung

o, q Siebförmige (kribröse) Mündung

p Ovale Mündung, fast ganz ausgefüllt mit einem flachen Zahn

$\mathrm{r} \quad$ Endständige (terminale) runde Mündung

$s \quad$ Einfache runde Mündung in der Stirnseite ( $=$ areale Mündung)

t Rhomboide Mündung

u Spaltenförmige Mündung mit Neigung zur Umbildung in eine siebförmige Mündung (vgl. q)

$\checkmark \quad$ Suturale Mündungen

w Modifizierte Mündung

x Bifider Zahn, pleurostomelline Mündung

y Kreuzförmige Mündung

z Einfache Mündung mit Apertural-Lippe 
Foraminiferen der Nordsee

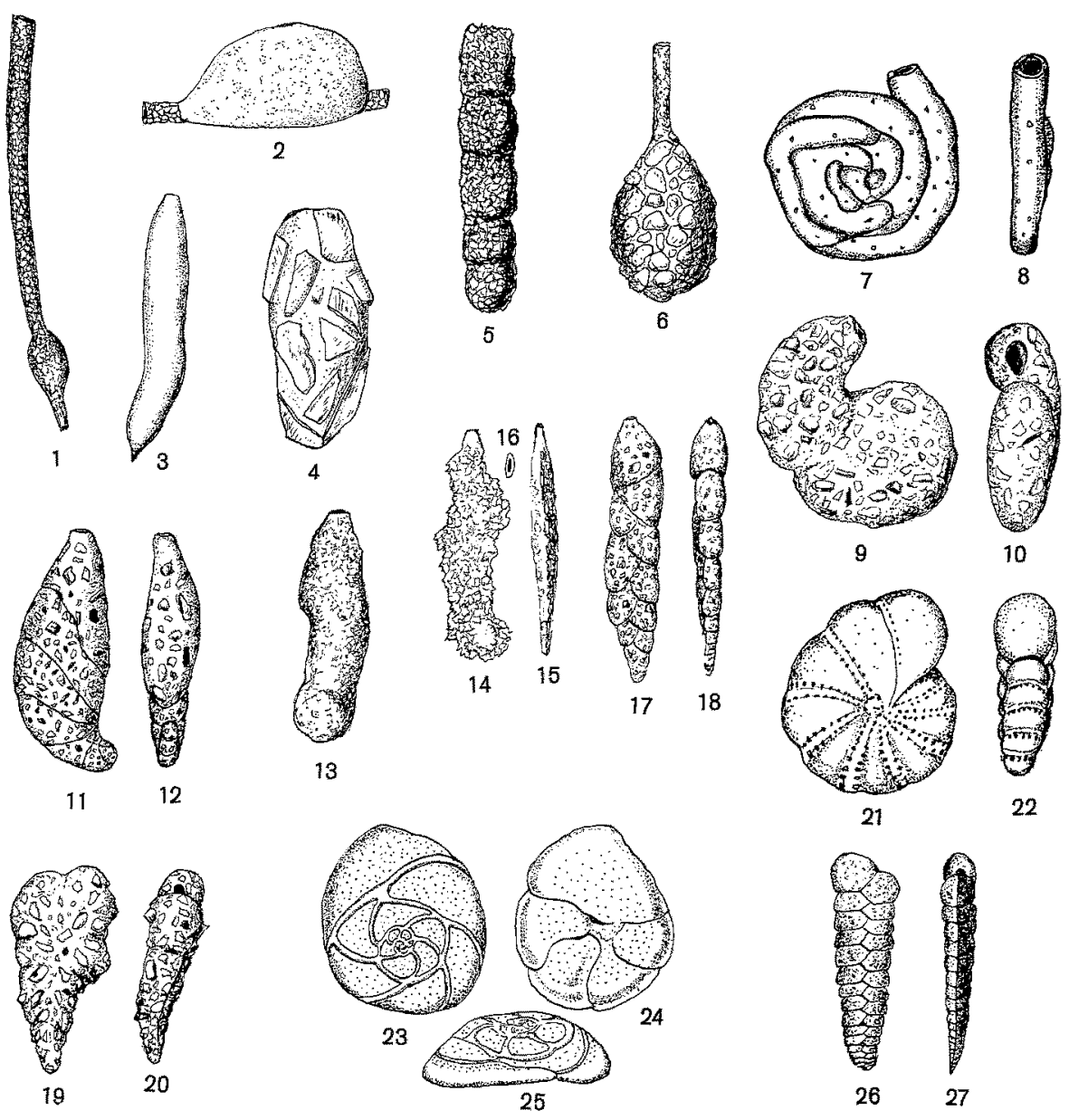

Mündungsformen

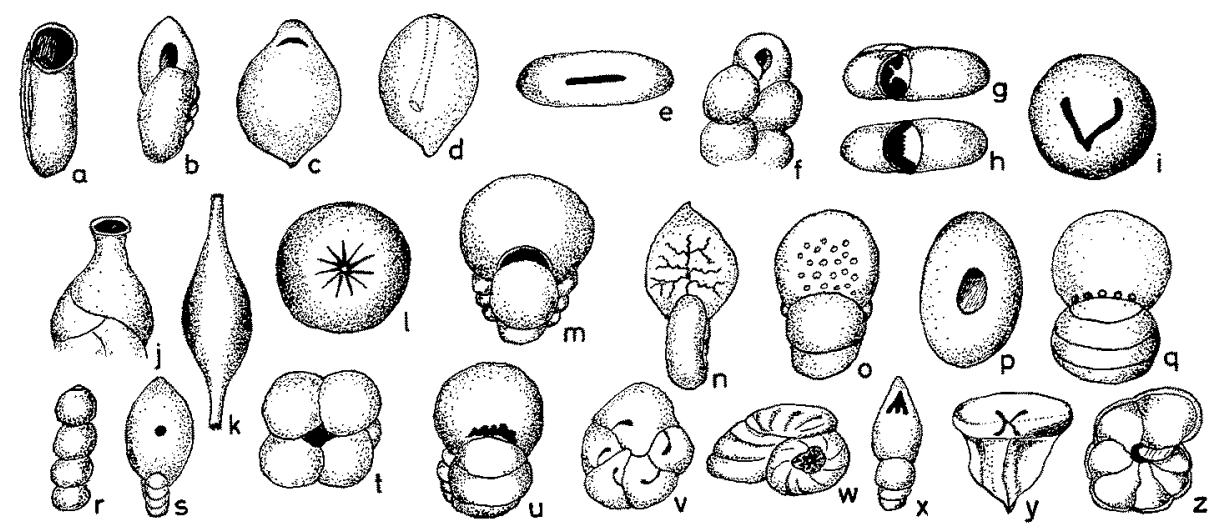

Tafel 20 